\title{
Small Break Air Ingress Experiment
}

Chang $\mathrm{H}$. Oh

Eung S. Kim

September 2011

The INL is a

U.S. Department of Energy

National Laboratory

operated by

Battelle Energy Alliance

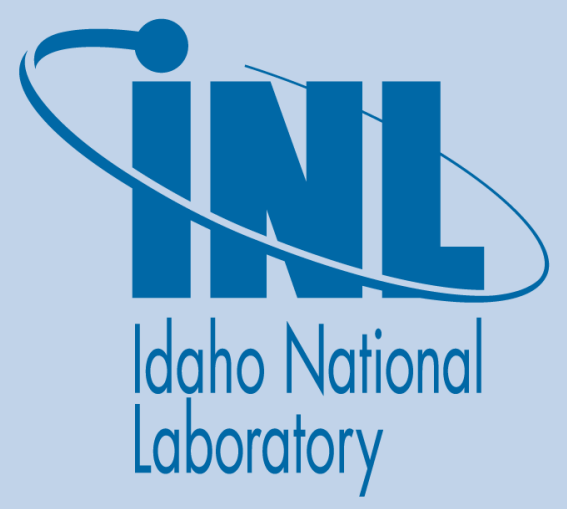

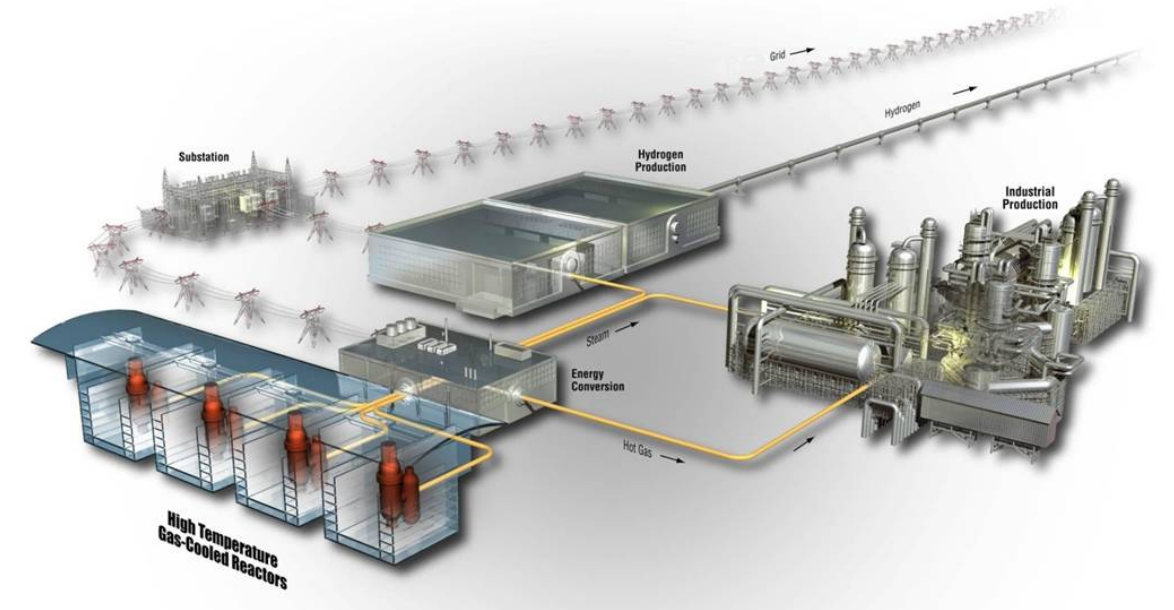




\section{DISCLAIMER}

This information was prepared as an account of work sponsored by an agency of the U.S. Government. Neither the U.S. Government nor any agency thereof, nor any of their employees, makes any warranty, expressed or implied, or assumes any legal liability or responsibility for the accuracy, completeness, or usefulness, of any information, apparatus, product, or process disclosed, or represents that its use would not infringe privately owned rights. References herein to any specific commercial product,

process, or service by trade name, trade mark, manufacturer, or otherwise, does not necessarily constitute or imply its endorsement, recommendation, or favoring by the U.S. Government or any agency thereof. The views and opinions of authors expressed herein do not necessarily state or reflect those of the U.S. Government or any agency thereof. 


\title{
Small Break Air Ingress Experiment
}

\author{
Chang H. Oh
}

Eung S. Kim

September 2011

Idaho National Laboratory

Next Generation Nuclear Plant Project

Idaho Falls, Idaho 83415

\section{http://www.inl.gov}

\section{Prepared for the}

U.S. Department of Energy

Office of Nuclear Energy

Under DOE Idaho Operations Office

Contract DE-AC07-05ID14517 



\section{Next Generation Nuclear Plant Project}

\section{Small Break Air Ingress Experiment}

INL/EXT-11-23380

September 2011

Approved by:
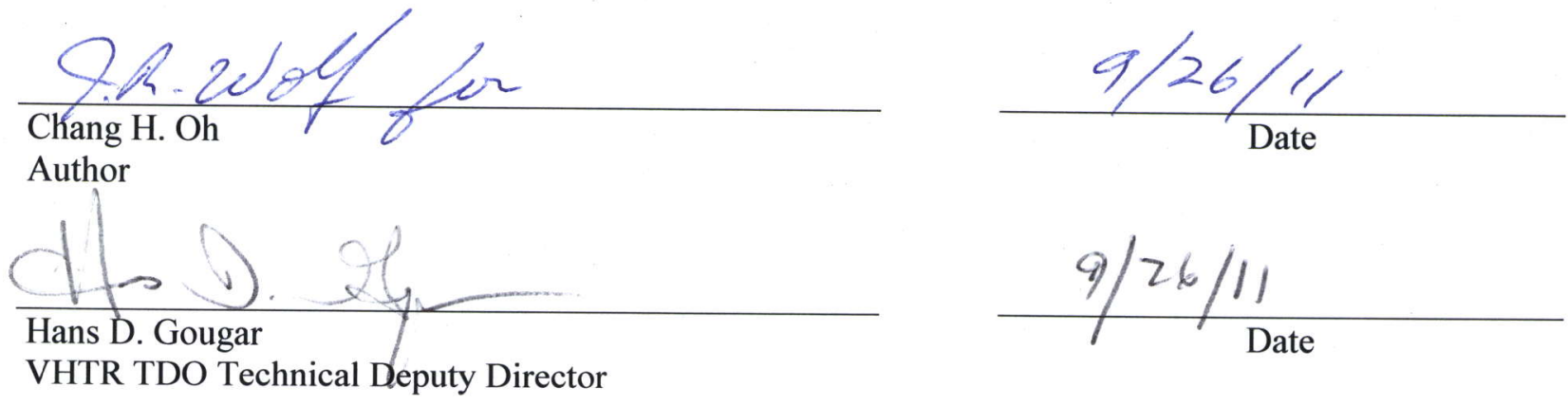



\begin{abstract}
This report describes the experimental planning, construction, and testing of the small break air ingress experiment performed at Idaho National Laboratory in FY 2011. The small break air-ingress experiment was designed to investigate airingress phenomena that might occur when a leak occurs in a pipe in a very high temperature reactor. This experiment measured air-ingress rates through a small hole in a pipe under various flow and break conditions. Several important parameters were examined, including break orientation, break size, and main flow velocity. The data obtained from this study will be used to better understand air-ingress phenomena and to assess/validate future computational fluid dynamics codes or system analysis codes.
\end{abstract}




\section{SUMMARY}

A loss-of-coolant accident is considered a design basis event for a very high temperature reactor. Following helium depressurization, it is anticipated that, unless proper countermeasures are taken, air ingress may occur, depending on the design, location, and orientation of the break. In the previous airingress research, most of the studies focused on a double-ended guillotine break leading to the most serious consequences. However, in reality, a small leak or break is a more probable accident than a double-ended guillotine break. This document summarizes the work performed on the experimental planning, construction, and testing of the small break air ingress experiments performed at the Idaho National Laboratory in FY 2011.

The small break air-ingress experiment described in this report is designed to investigate air-ingress phenomena postulated to occur in pipes in a very high temperature gas-cooled reactor. During this experiment, air-ingress rates were measured for various flow and break conditions through small holes drilled into a pipe of the experimental apparatus. The holes were drilled at right angles to the pipe wall such that a direction vector drawn from the pipe centerline to the center of each hole was at right angles with respect to the pipe centerline. The orientation of each hole was obtained by measuring the included angle between the direction vector of each hole with respect to a reference line anchored on the pipe centerline and pointing in the direction of the gravitational force. Using this reference system, the influence of several important parameters on the air ingress flow rate were measured including break orientation, break size, and flow velocity. The approach used to study the influence of these parameters on air ingress is based on measuring the changes in oxygen concentrations at various locations in the helium flow circulation system as a function of time, using oxygen sensors (or detectors) to estimate the air-ingress rates through the holes. The test-section is constructed of a stainless-steel pipe which had small holes drilled at the desired locations.

A significant quantity of data of sufficient quality to serve as the basis for performing validation of computational fluid dynamics (CFD) software was obtained. The data show the change in air ingress as a function of hole orientation, hole size, and flow rate in the system pipe. These data show that the hole orientation has a significant effect on the air ingress mechanism and flow rate. The air ingress rate increases with hole angles from 0 to 135 degrees (where the reference angle is the included angle between the reference line and the direction vector of each hole) as the density gradient is enhanced with increasing angle. For angles greater than 135 degrees, the air ingress rate decreases sharply as sustained countercurrent flow becomes unachievable and instead is either outgoing or incoming. The minimum air ingress rate is observed at 0 degrees and the maximum at 135 degrees. In general, the experimental results show that the flow rate increases as the hole size increases. This result is also enhanced by increasing density differences. However, enhancement of the flow rate that stems from increased density ratios were not significant compared to the influence of the hole orientation. Also, increased flow rates in the pipe of the experimental apparatus increases the air-ingress rate. The increase of the air-ingress rate with the flow rate may possibly be attributed to increase of flow instability around the hole when the flow passes through it. Because of the flow inside the channel, molecular diffusion controlled regimes were not observed in the small break air-ingress experiment even though the flow speed is very low-within the range of general natural circulation flow.

The experimental data obtained in this experiment can be directly used in the near future for comparisons with the CFD codes to validate CFD methods. These comparisons are currently planned in the next fiscal year. By accumulating more experimental data from various conditions, the data can eventually be used in development of analytical (or empirical) models for system analysis codes. For these reasons, future investigations are required. 


\section{E-1. Research Objectives}

The objectives of this study are to (1) better understand key phenomena that influence the air ingress into a VHTR following the initiation of a system leak, (2) provide experimental data as a basis for validating CFD software, and (3) provide data as the basis for the development of correlations that may be used in system analysis codes. The following activities were performed in FY 2011 as a level 4 milestone:

- The small break air-ingress experimental facility was planned, designed, manufactured, and installed

- A series of small break air-ingress scoping experiments were performed

- The experimental data were analyzed and an expanded understanding of air-ingress phenomena for small leaks was achieved. 


\section{CONTENTS}

ABSTRACT

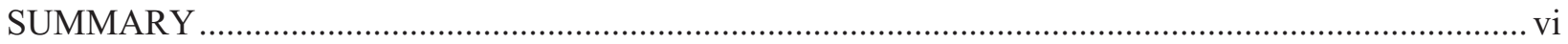

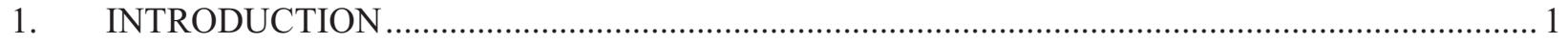

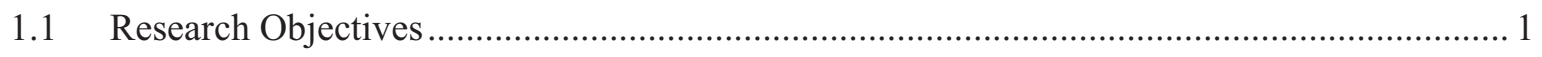

2. EXPERIMENTAL STUDY ON THE SMALL BREAK AIR-INGRESS ACCIDENT .................... 2

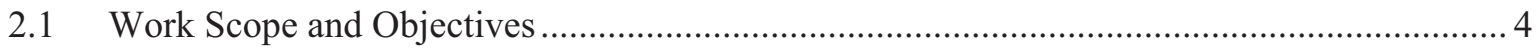

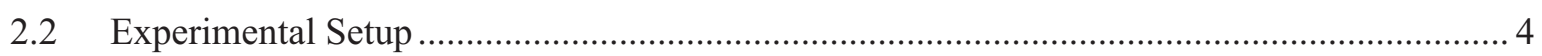

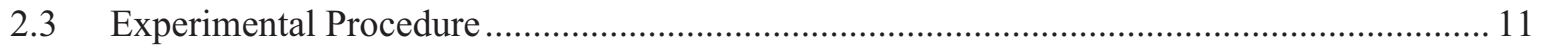

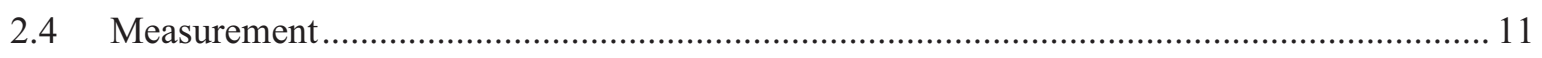

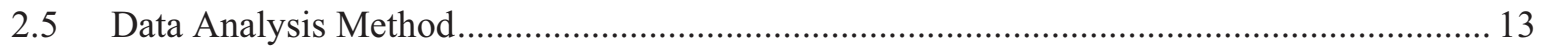

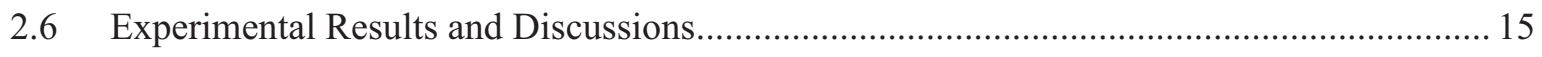

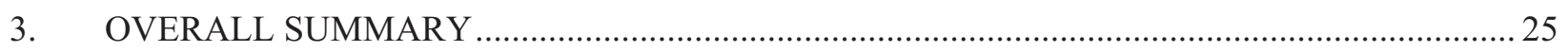

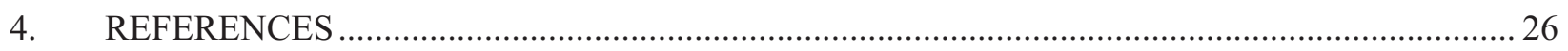

\section{FIGURES}

Figure 2-1. Three different regimes created, depending on the break angle of the hole (Oh et al. 2010). 2

Figure 2-2. Diffusion regime (break angle $=0$ degrees) $($ Oh et al. 2010) .............................................2

Figure 2-3. Stratified flow regime (break angle $=112.5$ degrees $)($ Oh et al. 2010) ................................ 3

Figure 2-4. Intermittent flow regime (break angle $=180$ degrees) $($ Oh et al. 2010) ................................. 3

Figure 2-5. Break angle vs. volumetric flow rate (Oh et al. 2010). ...................................................... 4

Figure 2-6. Schematic of small break air-ingress experimental facility. ................................................... 6

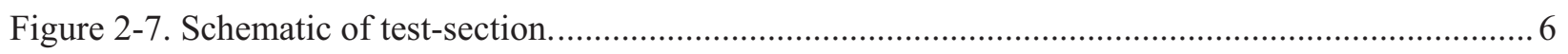

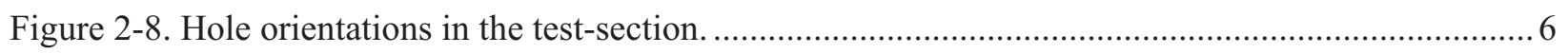

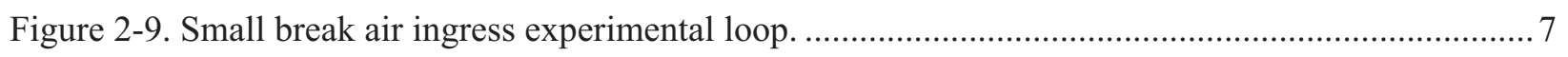

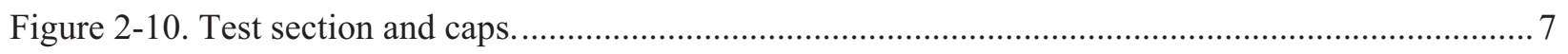

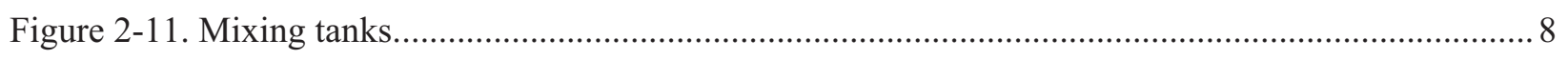

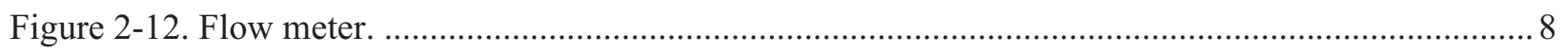

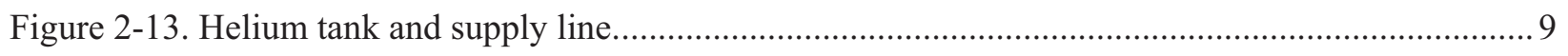

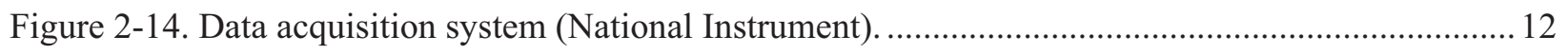

Figure 2-15. Screenshot of the Labview program for small break air-ingress experiment....................... 12

Figure 2-16. Screenshot of the Labview program for small break air-ingress experiment (model diagram)...... 


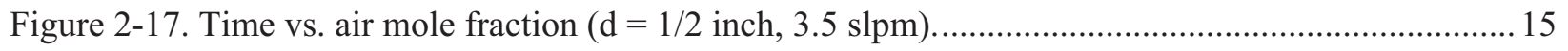

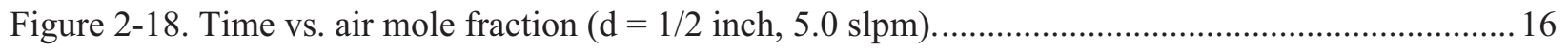

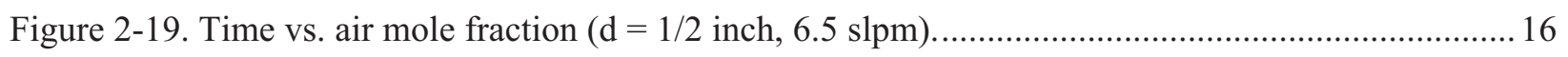

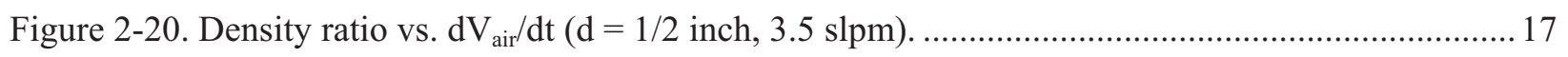

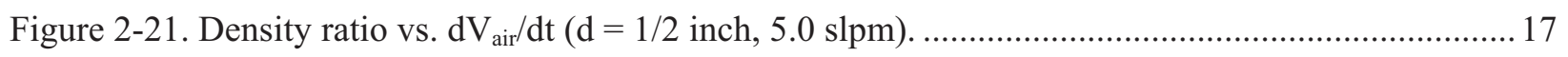

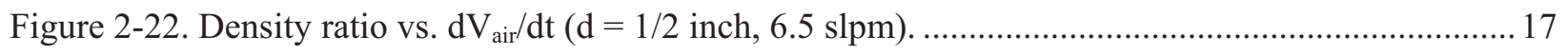

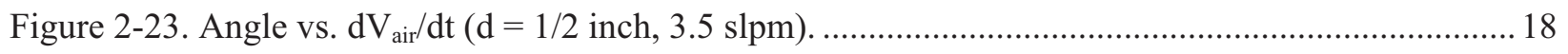

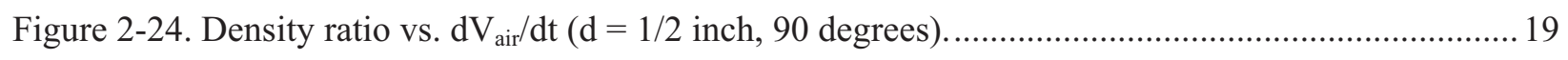

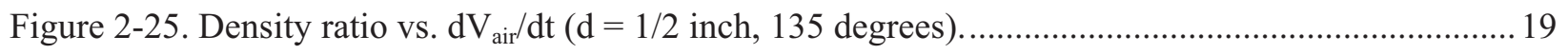

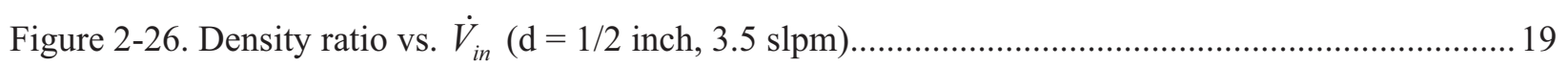

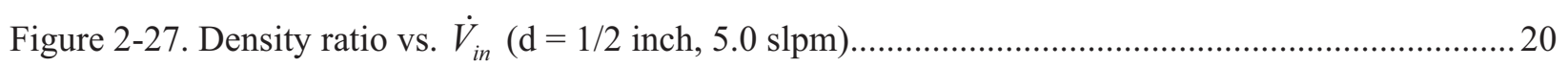

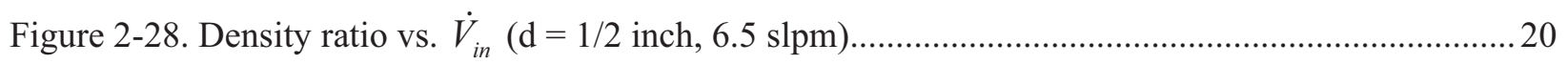

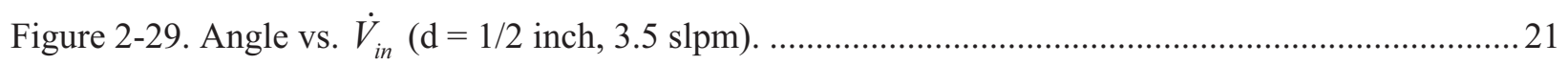

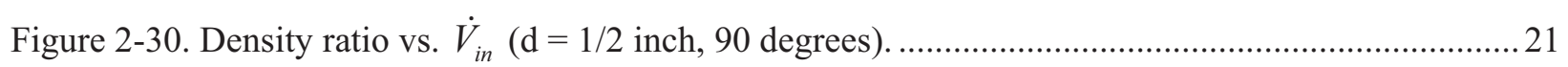

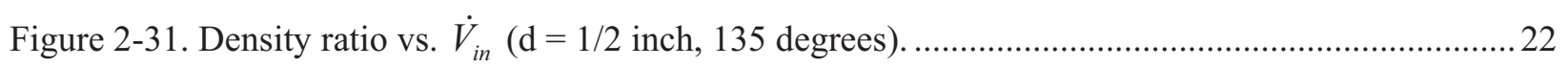

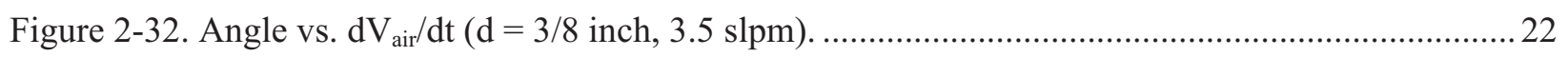

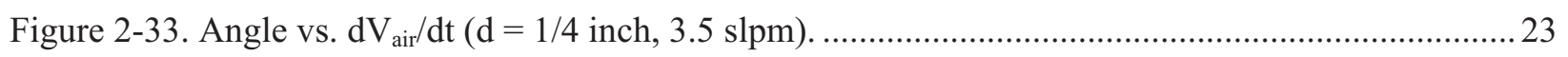

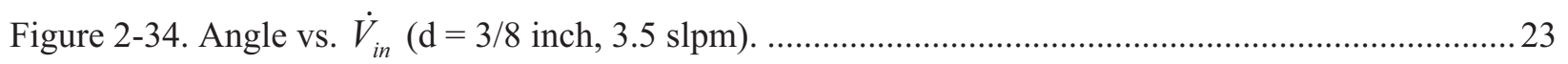

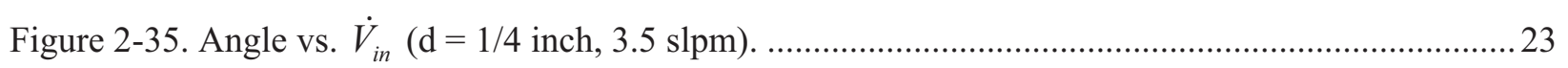

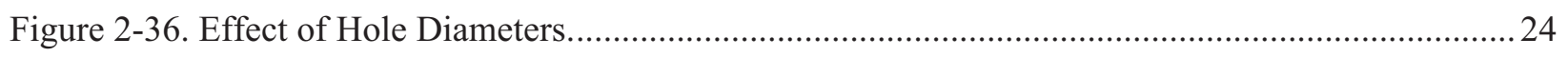

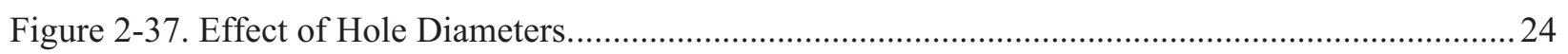

\section{TABLES}

Table 2-1. Specifications of major components and software in the small break air-ingress experiment. 


\section{Small Break Air Ingress Experiment}

\section{INTRODUCTION}

A loss-of-coolant accident is considered a design basis event in a very high temperature reactor (VHTR). Following helium depressurization, it is anticipated that, unless proper countermeasures are taken, air ingress may occur, depending on the design, location, and orientation of the break.

The U.S. Department of Energy is performing research and development that focuses on key phenomena important during challenging scenarios that may occur in the Next Generation Nuclear Plant (NGNP)/Generation IV VHTR. Phenomena Identification and Ranking Table studies have identified the air ingress event, following on the heels of a VHTR depressurization, as very important (Schultz et al. 2006). Consequently, the development of advanced air ingress-related models and verification and validation requirements are high priorities for the NGNP Project.

The highest probability leak scenarios, leading to air ingress into the reactor system, stem from having small leaks in the reactor system pressure boundary. Therefore, the experimental series described herein focused on quantifying the relationship between air ingress rates as a function of hole size (where the hole diameter is a fraction of the pipe diameter), hole orientation, and system conditions.

\subsection{Research Objectives}

This report describes the experimental planning, construction, and testing of the small break air ingress experiments performed at Idaho National Laboratory in FY 2011. The small break air-ingress experiment was designed to investigate air-ingress phenomena that might occur when a leak occurs in a pipe in the VHTR. This experiment measured air-ingress rates through a small hole in a pipe under various flow and break conditions. Several important parameters were examined, including break orientation, break size, and main flow velocity. The data obtained from this study will be used to better understand air-ingress phenomena and to assess/validate computational fluid dynamics (CFD) codes or system analysis codes. 


\section{EXPERIMENTAL STUDY ON THE SMALL BREAK AIR-INGRESS ACCIDENT}

Some computational and theoretical work was previously carried out for investigating the behavior of a small break air-ingress accident (Oh et al. 2010). One of the most important aspects in the small break situation is that the flow characteristics are highly dependent on the location of the leak with respect to the pipe centerline as well as the orientation of the pipe itself. Figure 2-1 shows some flow regimes observed in the previous computational studies. In this work, the initial flows in the inside and outside were assumed stagnant. The figures show a cross-sectional view of a horizontally-oriented circular pipe. The pipe is initially filled with helium (light fluid), while outside the cylinder is initially filled with air (heavy fluid.)

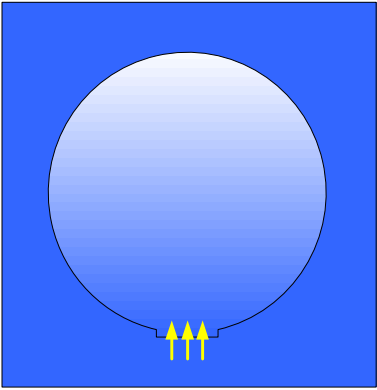

(a) Diffusion

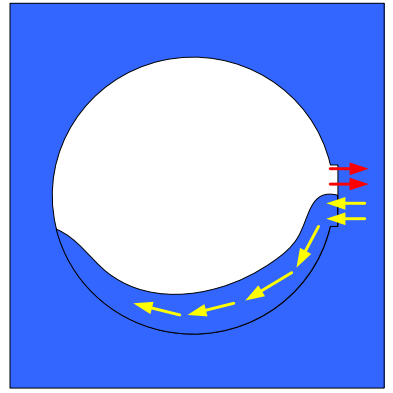

(b) Stratified Flow

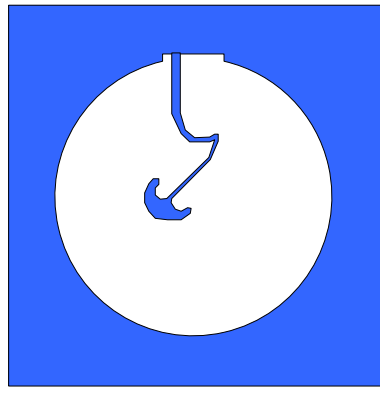

(c) Intermittent Flow

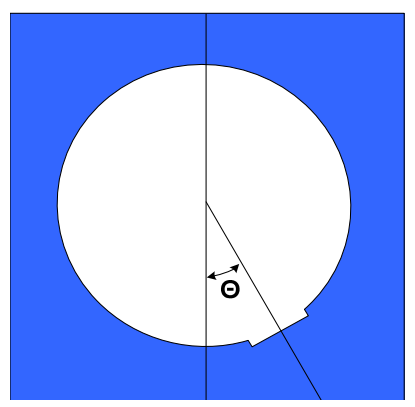

(d) Angle of the hole

Figure 2-1. Three different regimes created, depending on the break angle of the hole (Oh et al. 2010).

As shown in Figure 2-1a, if the leak is located on the bottom of the horizontal pipe (angle theta $=0$ degrees - see Figure 2-1d), the flow into the pipe is dominated by molecular diffusion. If the pipe is oriented so the flow is driven by density gradients, the heavier fluid (air) moves into the pipe through the lower region of the hole as stratified counter current flow occurs with the helium moving out of the pipe through the upper region of the hole (see Figure 2-1b). Finally, if the hole is located on the top of the horizontal pipe, the flow into and out of the pipe is intermittent as first air moves into the pipe until the pipe pressure becomes large enough to reverse the flow such that the gases in the pipe flow out of the hole into the atmosphere (see Figure 2-1c). Outward flow continues until the pipe pressure decreases sufficiently for the flow to once again reverse. This process continues in a cyclic fashion.

Figure 2-2 shows the simulation results for break angle $=0$ degrees, which represents the first regime (diffusion). The diffusion regime is very slow, as predicted, and no noticeable changes occur in a timescale of 10 seconds.

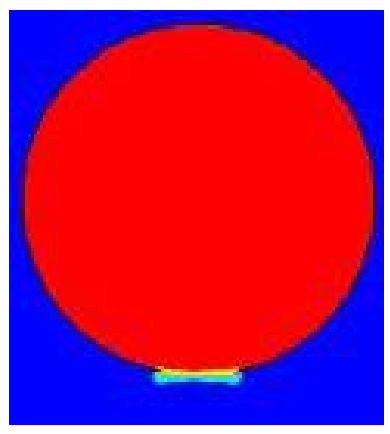

$\mathrm{t}=0$ seconds

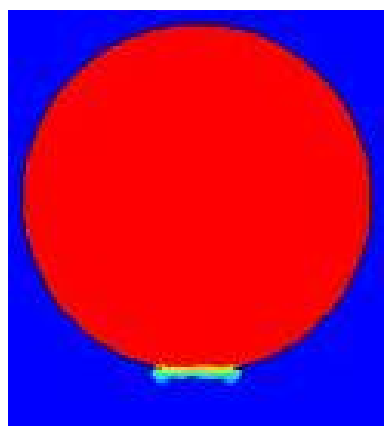

$\mathrm{t}=5$ seconds

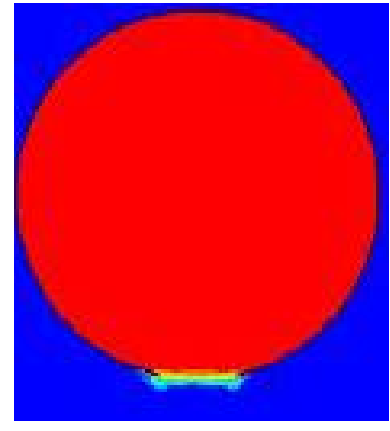

$\mathrm{t}=10$ seconds

Figure 2-2. Diffusion regime (break angle $=0$ degrees) (Oh et al. 2010). 
Figure 2-3 shows the simulation results for a break angle $=112.5$ degrees, which represents the second regime (stratified flow). In Figure 2-3, the red circle is the cross-section of the pipe with the leak and the blue annulus represents the air-filled pipe that surrounds the pipe. At the beginning of the transient, air enters the cylinder because of a positive density difference. Gravitational forces cause the flow to follow the contour of the pipe inner wall surface up to the elevation of the hole. Thereafter mixing between the helium and air begin within the pipe.

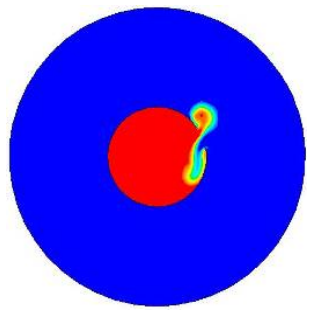

$\mathrm{t}=1 \mathrm{sec}$

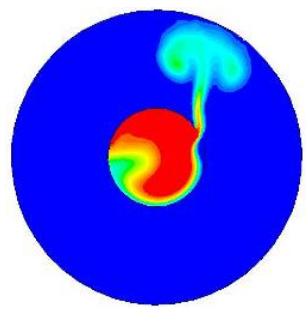

$\mathrm{t}=3 \mathrm{sec}$

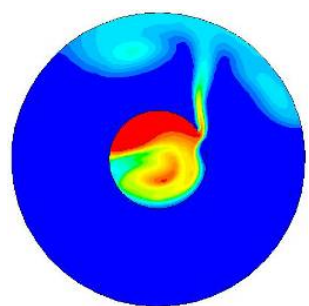

$\mathrm{t}=5 \mathrm{sec}$

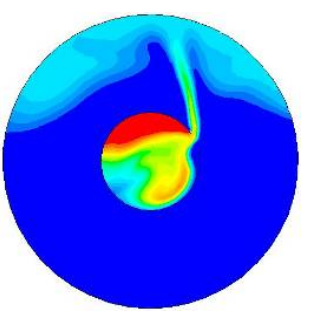

$\mathrm{t}=7 \mathrm{sec}$

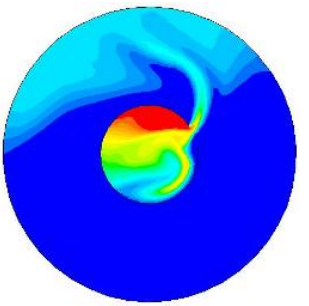

$\mathrm{t}=9 \mathrm{sec}$

Figure 2-3. Stratified flow regime (break angle $=112.5$ degrees) (Oh et al. 2010).

Figure 2-4 shows the simulation results for break angle $=180$ degrees, which shows intermittent flow into and out of the pipe. Air cannot flow directly along the bottom of a helium flow because of the orientation of the hole. The initial interface is unstable and the interface will roll-up. This helium bubble created within the outer tank is mirrored by an air bubble within the inner volume. The process of this exchange creates a pulsed flow across the break.

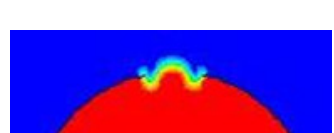

$\mathrm{t}=1 \mathrm{sec}$

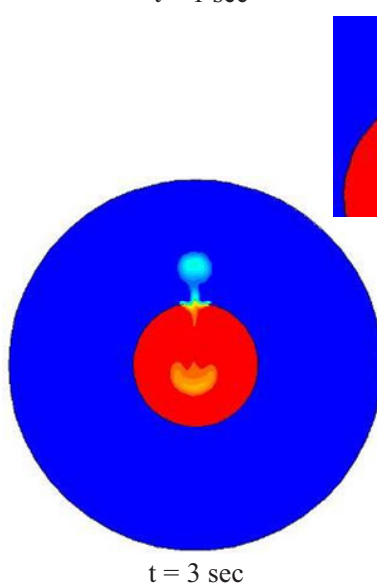

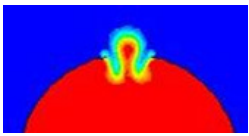

$\mathrm{t}=1.5 \mathrm{sec}$

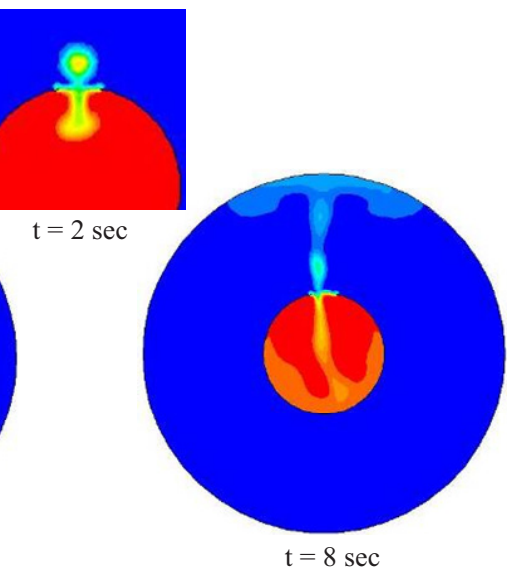

Figure 2-4. Intermittent flow regime (break angle $=180$ degrees) (Oh et al. 2010). 
Figure 2-5 shows the relations between break angles and maximum air flow rates. Air flow initially increases with break angle and peaks around 125 degrees. The flow rate then rapidly drops with angle, owing to the development of intermittent flow. When the break angles reach 180 degrees, the flow rate is less than $25 \%$ of the maximum flow rate.

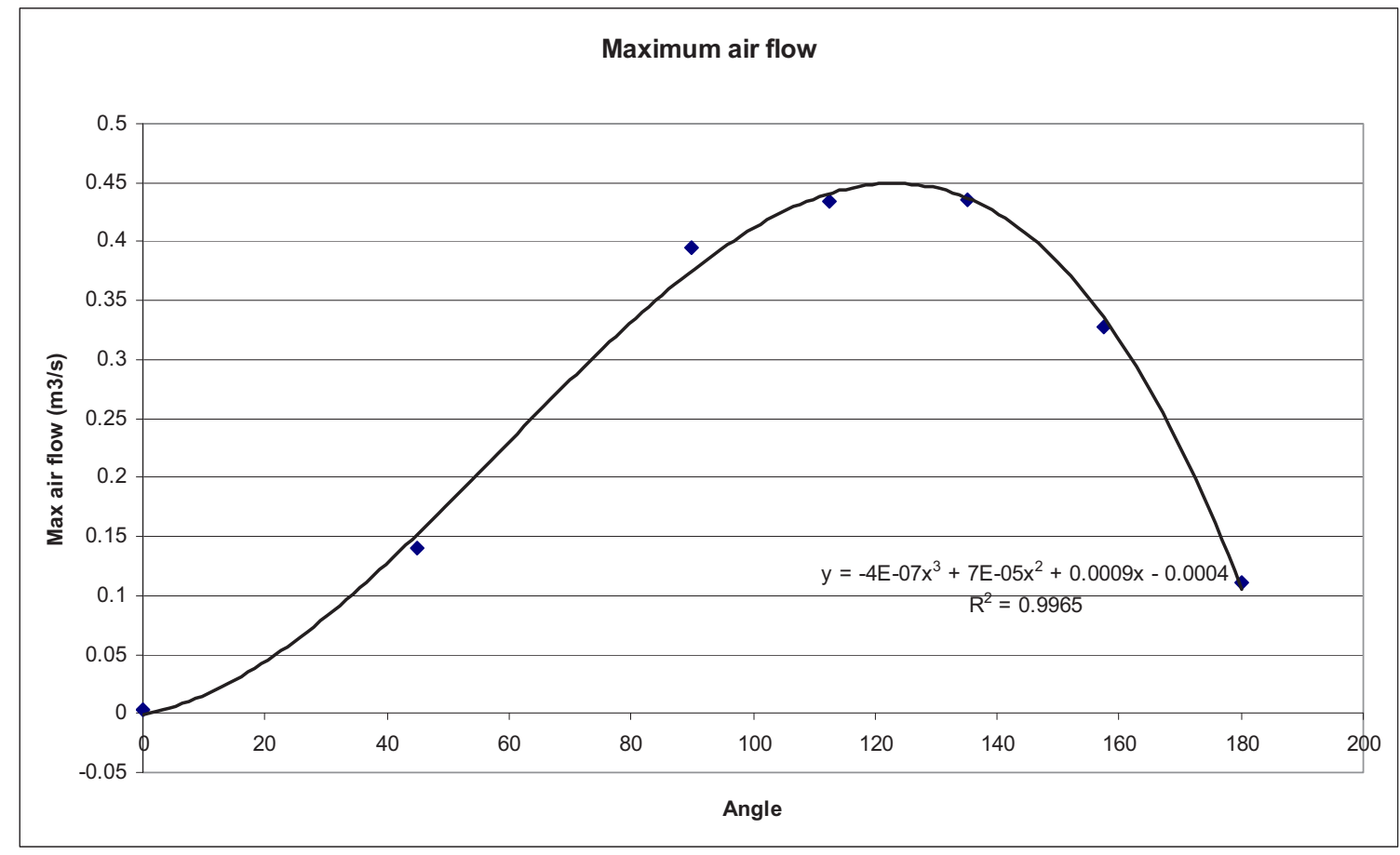

Figure 2-5. Break angle vs. volumetric flow rate (Oh et al. 2010).

Although some computational work was previously conducted for small break situations, there has been no experimental data available to support the numerical observations until the experimental series described in this report was performed. These data will be used to validate CFD codes and to develop models to use in system analysis codes.

\subsection{Work Scope and Objectives}

The small break air-ingress experiment was designed to investigate air-ingress phenomena that occur in VHTRs. This experiment measures air-ingress rates through a small hole in a broken pipe model at various flow and break conditions. Several important parameters were investigated during this experiment, including break orientation, break size, main flow velocity, and tube thickness. The main objectives of this study were as follows:

- Design and manufacturing of an experimental facility to demonstrate fundamental air-ingress phenomena in the small break accident.

- Generating experimental data to support (1) an improved understanding of small break air-ingress phenomena, (2) CFD validation methods, and (3) development of analytical/empirical model for system codes.

\subsection{Experimental Setup}

Although the calculations were performed assuming stagnat conditions in both the pipe and the adjacent atmosphere outside the pipe, the experiments were performed in a way that was more 
representative of the flow conditions that would exist in a VHTR, that is, natural circulation was assumed inside the system piping. Representative natural circulation conditions were simulated in the experimental facility using a circulator designed to produce low flow rates. Air ingress into the pipe test section was monitored by using oxygen sensors, and the rate of change of oxygen concentration was used to calculate the air ingress rate into the pipe test section and experimental facility. Various sized leaks were simulated by using three different diameter hole sizes ( $1 / 4$ inch, $3 / 8$ inch, and 1/2 inch diameter) Holes of a particular diameter were drilled into the pipe wall at a specific plane normal to the pipe flow area. Five holes of the same diameter were located at various angles with respect to the reference. The experiment was conducted at room temperature and atmospheric pressure. The oxygen concentration and flow rate data will be stored in the computer by a data acquisition system (DAS).

Figures 2-6 and 2-7 show the basic geometry of the small break air-ingress experimental setup and the test-section. This experiment consists of the following major components:

- Test section: Test section is made of a circular pipe (2 inch inner diameter) with holes around it for mimicking a small break situation in the VHTR. During the experiment, all holes except for one are closed. In this experiment, the test-section is made of stainless steel, and nylon caps were used to plug the holes.

- Circulator: The circulator circulates air/helium mixture in the test loop. The circulator speed is adjustable and was set to simulate natural circulation conditions. This circulator was designed to provide the same volumetric flows regardless of types of mixtures.

- Mixing tank: The mixing tank was designed to stabilize flow and enhance the mixing of it. The mixing tank contains the circulator and various instruments, including a thermocouple, pressure transducer, pressure gauge, and oxygen sensor. The mixing tank was made of acrylic plastic.

- Flow meter: The flow meter measures flow rates of the working fluids (mainly helium). Since the mixture concentrations are changing during the experiment, a coriolis flow meter was used in this experiment, which is not sensitive to the types of fluids. The maximum measurable flow rates are 50 slpm (standard liters per minute), and the measurement ranges can be easily adjusted using software.

- Oxygen sensor: The oxygen sensor measures oxygen concentrations $(0 \sim 25 \%)$ in the fluid. The oxygen sensor was installed in the mixing tank. This experiment used a zirconium based sensor commercially used in the process industry.

Figure 2-6 is a schematic of the small break experiment. This test-loop was initially filled with helium gas, and the flow was induced by the circulator. When the flow was stabile and the system achieved a steady-state condition, a cap on the desired hole located on the test-section was un-plugged to allow air to enter the system. During the experiment, oxygen concentration, flow rates, temperature, and pressure were monitored and recorded by a DAS and Labview software. Figure 2-7 shows a schematic of the testsection. Holes with three different diameters were drilled on the test-section wall: $1 / 4 \mathrm{inch}, 3 / 8 \mathrm{inch}$, and $1 / 2$ inch. The holes were drilled at right angles to the pipe wall such that a direction vector drawn from the pipe centerline to the center of each hole was at right angles with respect to the pipe centerline. Thus, the orientation of each hole was obtained by measuring the included angle between the direction vector of each hole with respect to a reference line anchored on the pipe centerline and pointing in the direction of the gravitational force. Using this reference system, holes were drilled at angles of $0,45,90,125$, and 180 degrees. Figure 2-8 shows the orientations of the holes. 


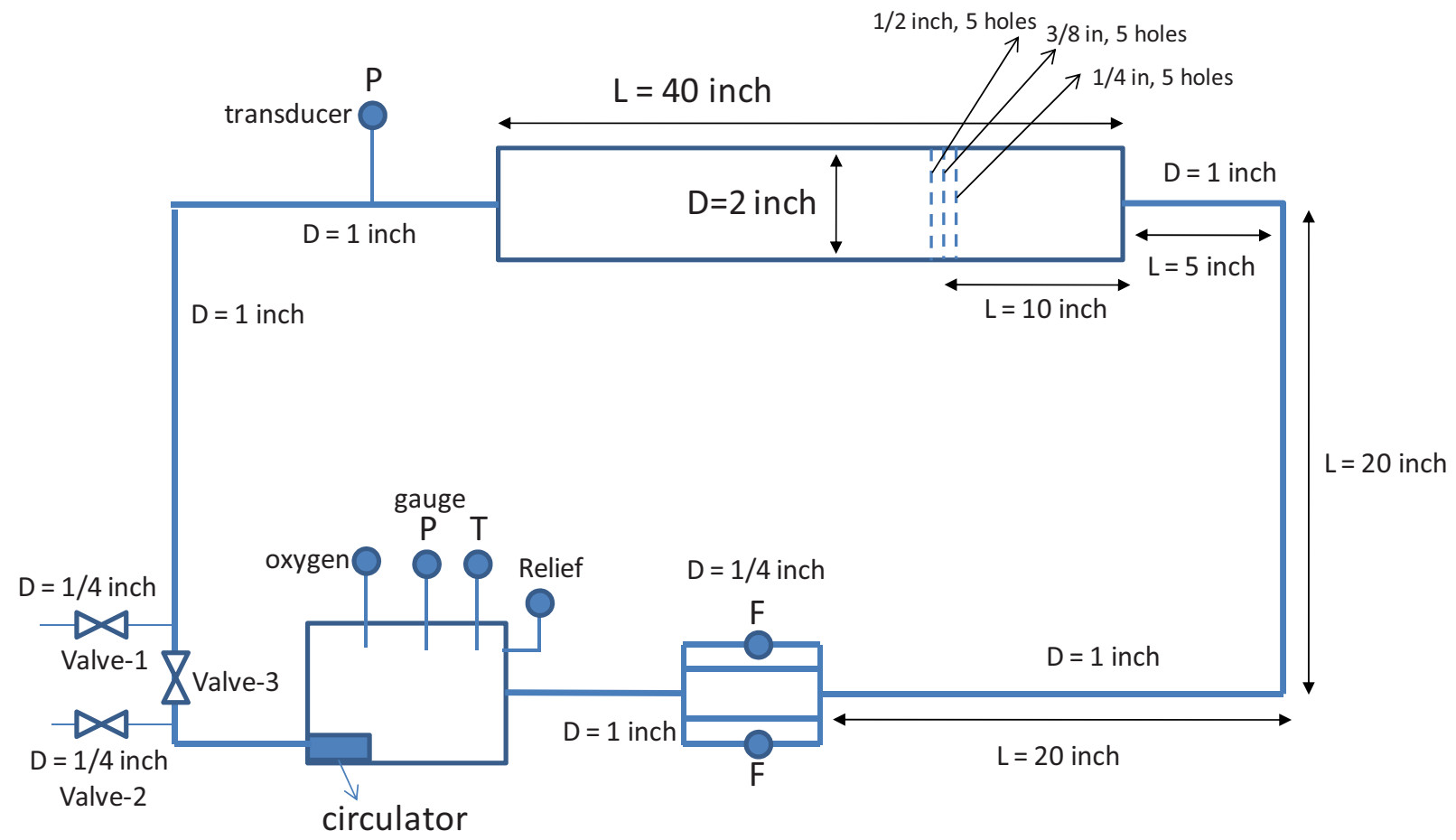

Figure 2-6. Schematic of small break air-ingress experimental facility.

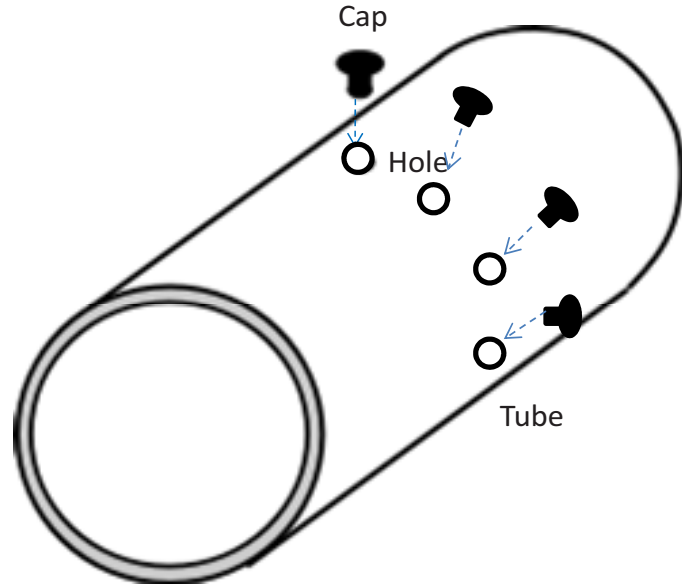

Figure 2-7. Schematic of test-section.

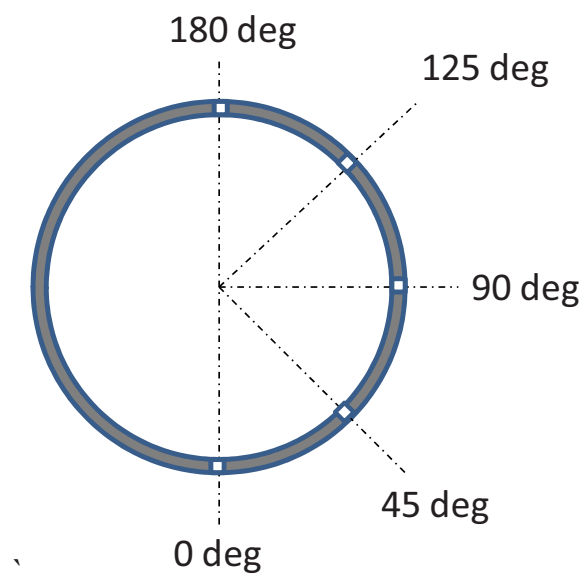

Figure 2-8. Hole orientations in the test-section.

The small break air-ingress experiment was operated at ambient temperature and atmospheric pressure. The system pressure was initially set at $1.1 \mathrm{~atm}$, but this pressure was reduced to $1 \mathrm{~atm}$ during the experiment. For safety reasons, two relief valves were installed in the system with the following set pressures: Relief-1 : $1.3 \mathrm{~atm}$; Relief-2 : $2.2 \mathrm{~atm}$.

The pipe diameter of the helium circulation loop is less than $1 \mathrm{inch}$. The test-section diameter is 2 inches. The two different size pipes are connected by reducers. For safety reason, the cap for the testsection was connected to the test section by a metallic wire.

During the experiment, the test-section and the flow loop was filled with helium. The helium was slowly released to atmosphere (outside the facility) to achieve the operating pressure. 
Figures 2-9 through 2-13 show pictures of the test facility, test-section and holes, mixing tank, instrument devices, flow meter, and helium supply setup. Table 2-1 summarizes major components and software used in the experiment.

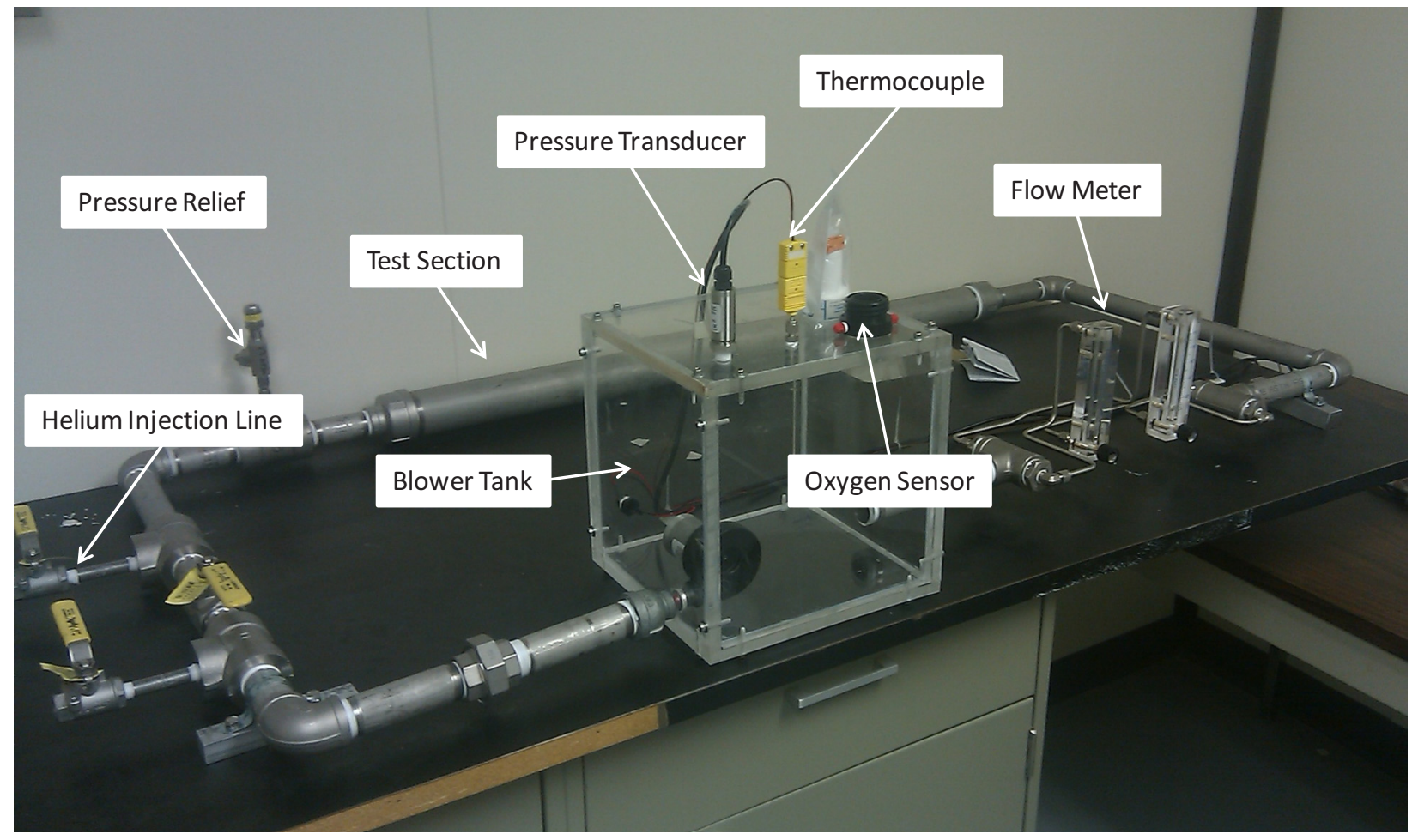

Figure 2-9. Small break air ingress experimental loop.

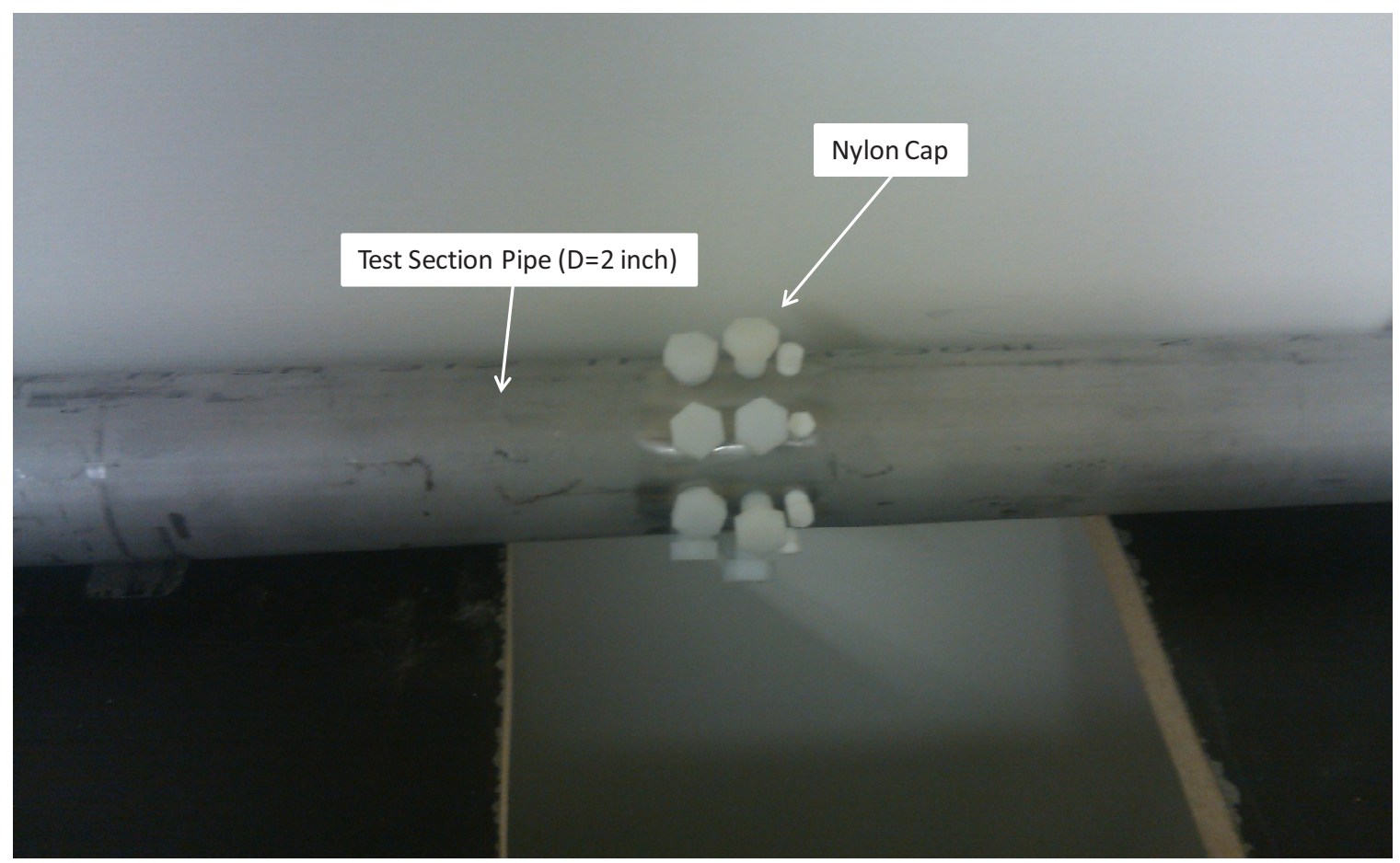

Figure 2-10. Test section and caps. 


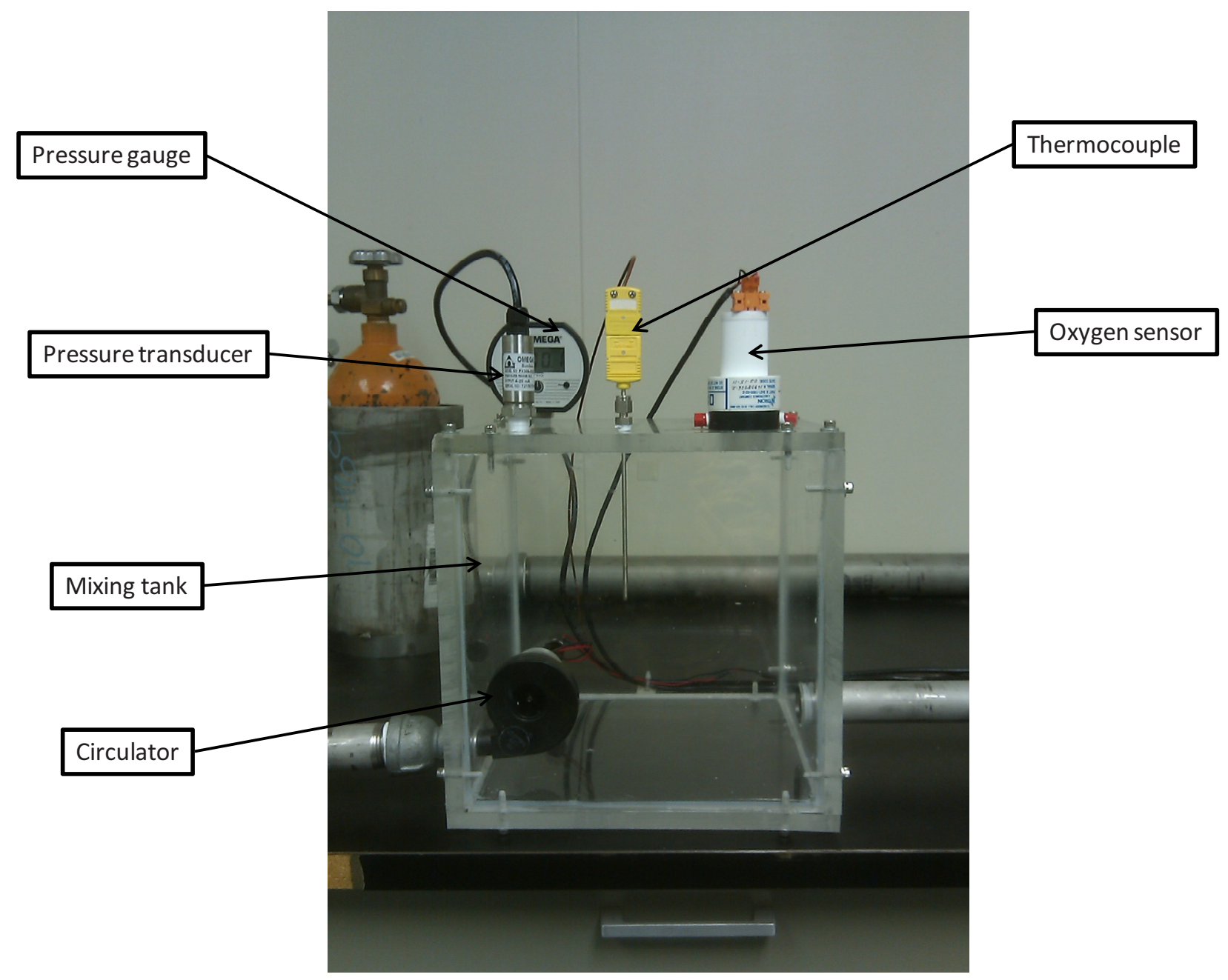

Figure 2-11. Mixing tanks.

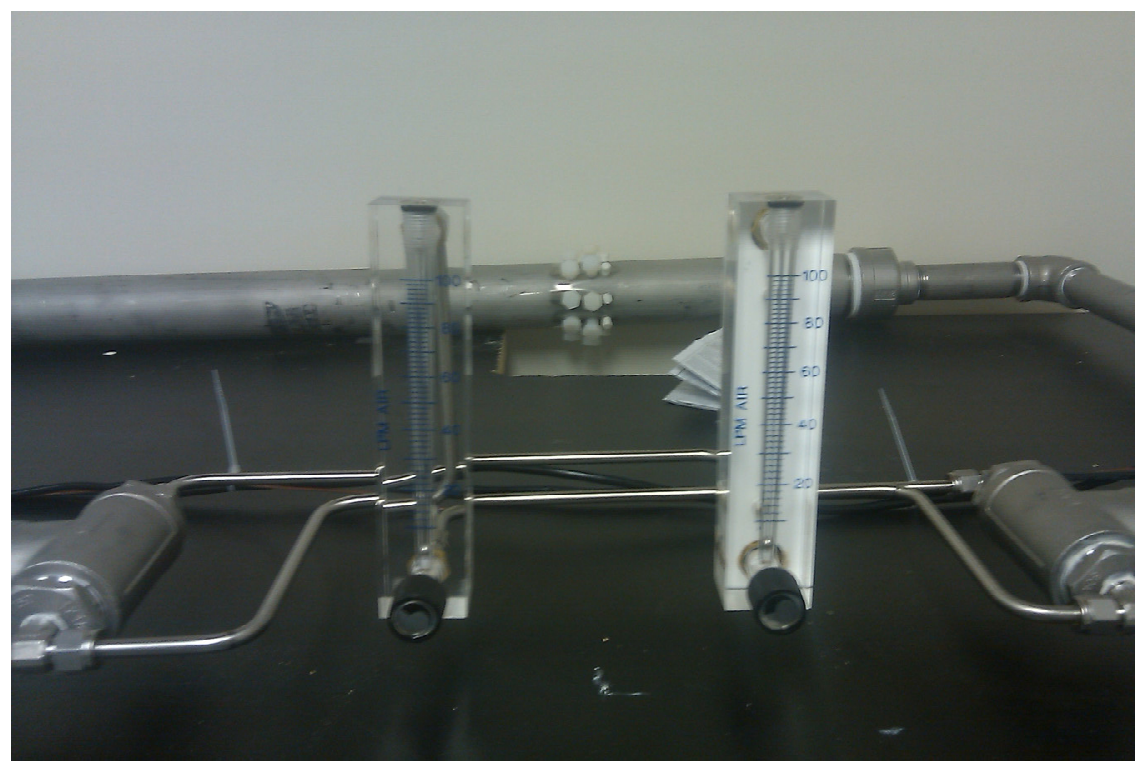

Figure 2-12. Flow meter. 


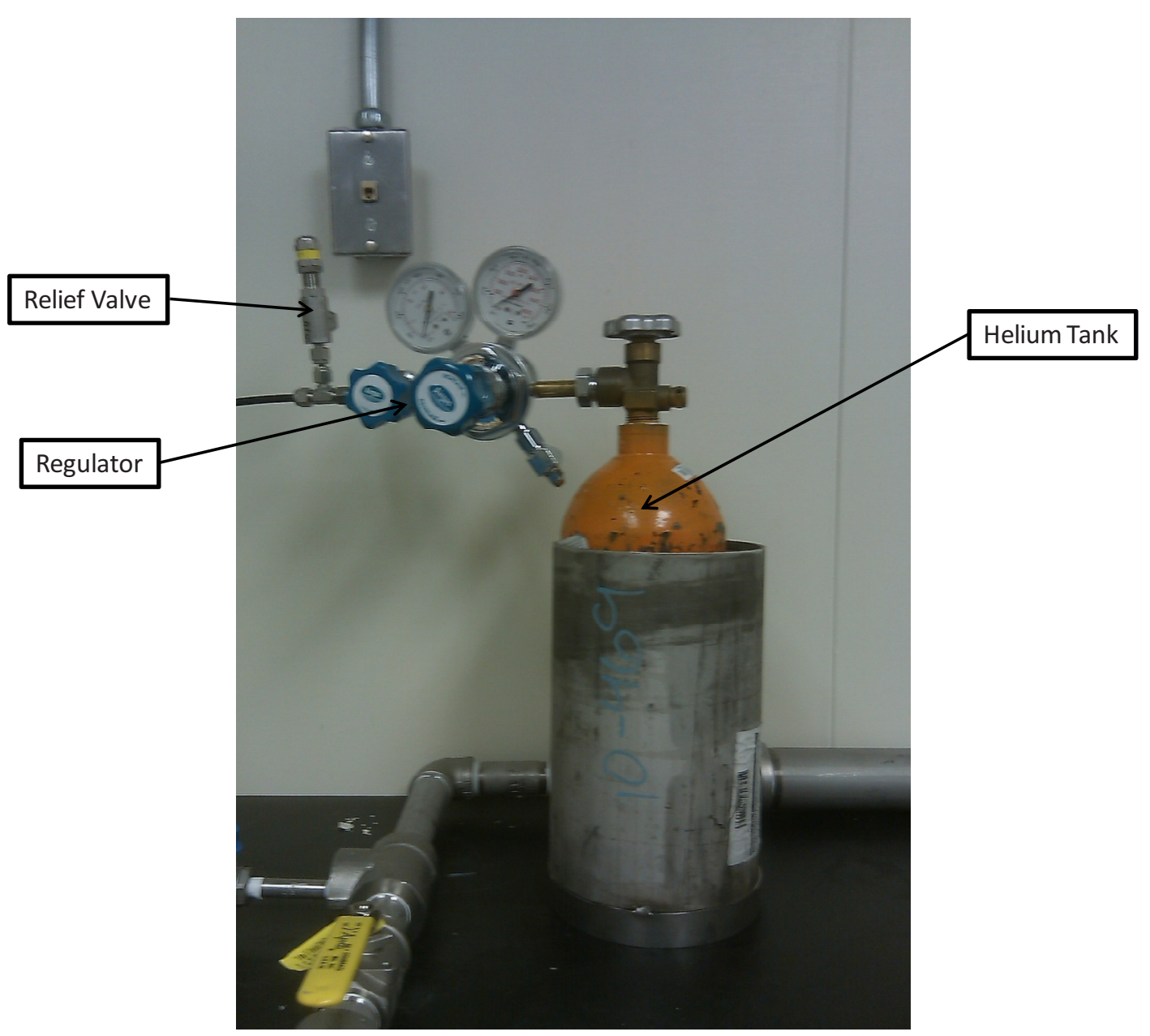

Figure 2-13. Helium tank and supply line.

Table 2-1. Specifications of major components and software in the small break air-ingress experiment.

\begin{tabular}{|lll|}
\hline \multicolumn{1}{|c|}{ Major Item } & \multicolumn{1}{c|}{ Manufacturer } & \multicolumn{1}{c|}{ Specifications } \\
\hline Circulator & AMTEK Technical & Low Voltage Brushless DC Blower \\
& \& Industrial Products & Model \#: 199494 \\
& Voltage: 6-14 V VC \\
& Stages: 1 \\
& Max Sealed Pressure: $92.4 \mathrm{mbar}$ \\
& Max Open Flow Rate: $18.5 \mathrm{~m}^{3} / \mathrm{hr}$ \\
Circulator Power & EPSCO Incorporated & Filtered DC Power Supply \\
Supply & Model \#: EC-2 \\
& & Power Requirements: $117 \mathrm{~V}, 50-60 \mathrm{~Hz}$ \\
& DC Output: 0-16 V VC at 5 A \\
& AC Ripple: Max. 0.5\% at rated load \\
& Load Regulation: $2.5 \mathrm{~V}$ \\
& DC Impedance: 2.5 ohms \\
\hline
\end{tabular}




\begin{tabular}{|c|c|c|}
\hline Major Item & Manufacturer & Specifications \\
\hline Pressure Transducer & OMEGA & $\begin{array}{l}\text { Stainless Steel Transducer } \\
\text { Model \#: PX309-002GI } \\
\text { Measurement Range: } 1-2 \mathrm{psi} \\
\text { Accuracy: } \pm 0.25 \% \\
\text { Total Error Band: } \pm 2.0 \% \\
\text { Long-Term Stability }(1 \text { year): } \pm 0.25 \% \text { typical } \\
\text { Operating temperature: }-40 \sim 85^{\circ} \mathrm{C} \\
\text { Response time: }<1 \mathrm{~ms} \\
\text { Output: } 4 \sim 20 \mathrm{~mA}\end{array}$ \\
\hline Flow meter & BROOKS & $\begin{array}{l}\text { Coriolis Flow meter } \\
\text { Model \#: QUANTIM } \\
\text { Measurement Range: 0-50 slpm (adjustable ranges) } \\
\text { Accuracy: } \pm 0.5 \% \\
\text { Repeatability: } \pm 0.05 \% \\
\text { Output: } 4 \sim 20 \mathrm{~mA}\end{array}$ \\
\hline Oxygen Sensor & NEUTRONICS Inc. & $\begin{array}{l}\text { Oxygen Transmitter } \\
\text { Model \#: MGT3 Oxygen Transmitter } \\
\text { Measurement Range: } 0 \sim 25 \% \\
\text { Accuracy: } \pm 2.0 \% \\
\text { Operating pressure: } 100 \text { bar } \\
\text { Operating temperature: } \sim 65^{\circ} \mathrm{C} \\
\text { Output: } 4 \sim 20 \mathrm{~mA}\end{array}$ \\
\hline Thermocouple & OMEGA & $\begin{array}{l}\text { K-type thermocouple } \\
\text { Accuracy: } \pm 0.75 \% \\
\text { Diameter: } 5 \mathrm{~mm}\end{array}$ \\
\hline $\begin{array}{l}\text { Data Acquisition } \\
\text { System }\end{array}$ & National Instrument & $\begin{array}{l}\text { Multi-function Data Acquisition System } \\
\text { Model \#: NI USB-6341 } \\
\text { Analog channel: } 16 \\
\text { Sample rate: } 500 \mathrm{kS} / \mathrm{s} \\
\text { Resolution: } 16 \text { bits }\end{array}$ \\
\hline Labview & National Instrument & $\begin{array}{l}\text { Visual programming language for instrument \& } \\
\text { control } \\
\text { Version: Labview } 2010 \text { (ver. } 10.0 \text { (32 bit)) }\end{array}$ \\
\hline
\end{tabular}




\subsection{Experimental Procedure}

The test procedure followed when performing the experiment is described below (all the tests were conducted in ambient temperature and pressure).

1. The type of test-section was selected (hole diameter and thickness).

2. The hole orientation was selected between 0 degrees and 180 degrees.

3. The test-section was installed into the experimental facility.

4. The cap on the test-section hole was closed.

5. The oxygen sensor and flow meter were switched on.

6. The Labview program was started.

7. Valve-1 and Valve -3 were closed and Valve -2 was opened.

8. The helium tank regulator pressure was set at $2.0 \mathrm{~atm}$ with the relief valve- 2 pressure set at $2.2 \mathrm{~atm}$.

9. Valve-1 was opened to inject helium into the facility (relief Valve-1 pressure was set at $1.3 \mathrm{~atm}$ ).

10. Once the facility pressure reached $1.1 \mathrm{~atm}$, Valve- 1 and Valve- 2 were closed.

11. Valve-3 was opened.

12. The circulator was switched on for circulating helium.

13. Once the system reached steady-state, the cap on the test-section was opened.

14. Oxygen concentration and flow rate data were monitored and stored in the computer.

15. After completing the experiment, the circulator was switched off.

16. Valve-1 was opened.

17. The oxygen sensor and the flow meter were switched off.

18. The hole location was rotated and the test procedure was repeated from (a) to (q) for the different location of the simulated break orientation.

\subsection{Measurement}

In this experiment, the following four parameters were measured. Data was recorded in a laboratory notebook and all instrumentation was calibrated per the manufacture's instructions. Specifications of the instruments are summarized in Table 2-1:

- Temperature

- Pressure

- Flow rate

- Oxygen concentration.

Figure 2-14 shows the data acquisition system used in this study, and Figures 2-15 and 2-16 show screenshots of the Labview program, which was made for receiving and recording data from the instruments. 


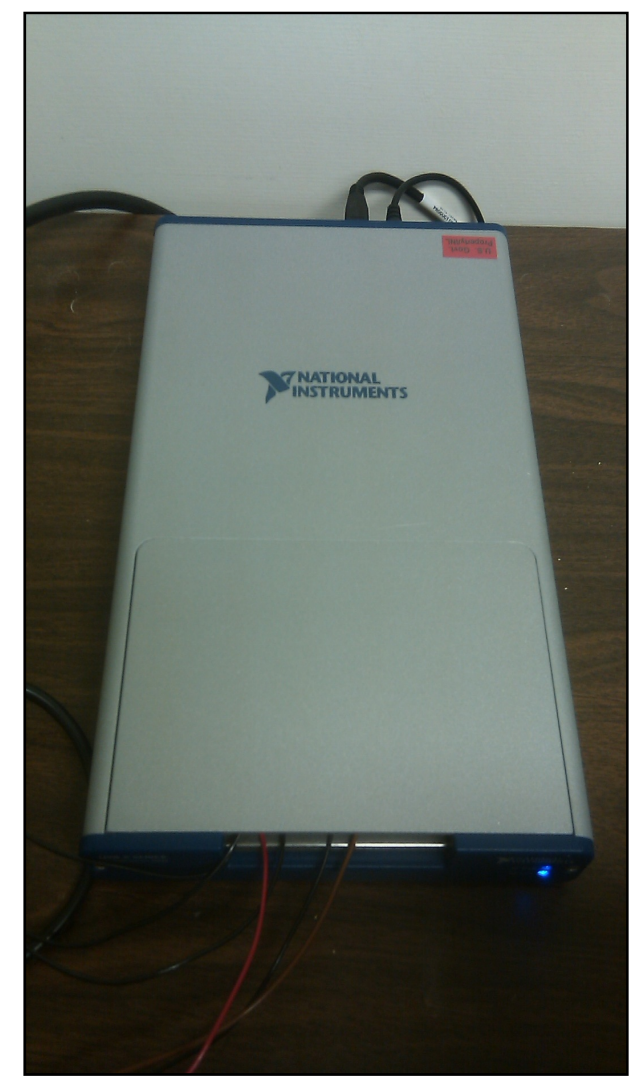

Figure 2-14. Data acquisition system (National Instrument).

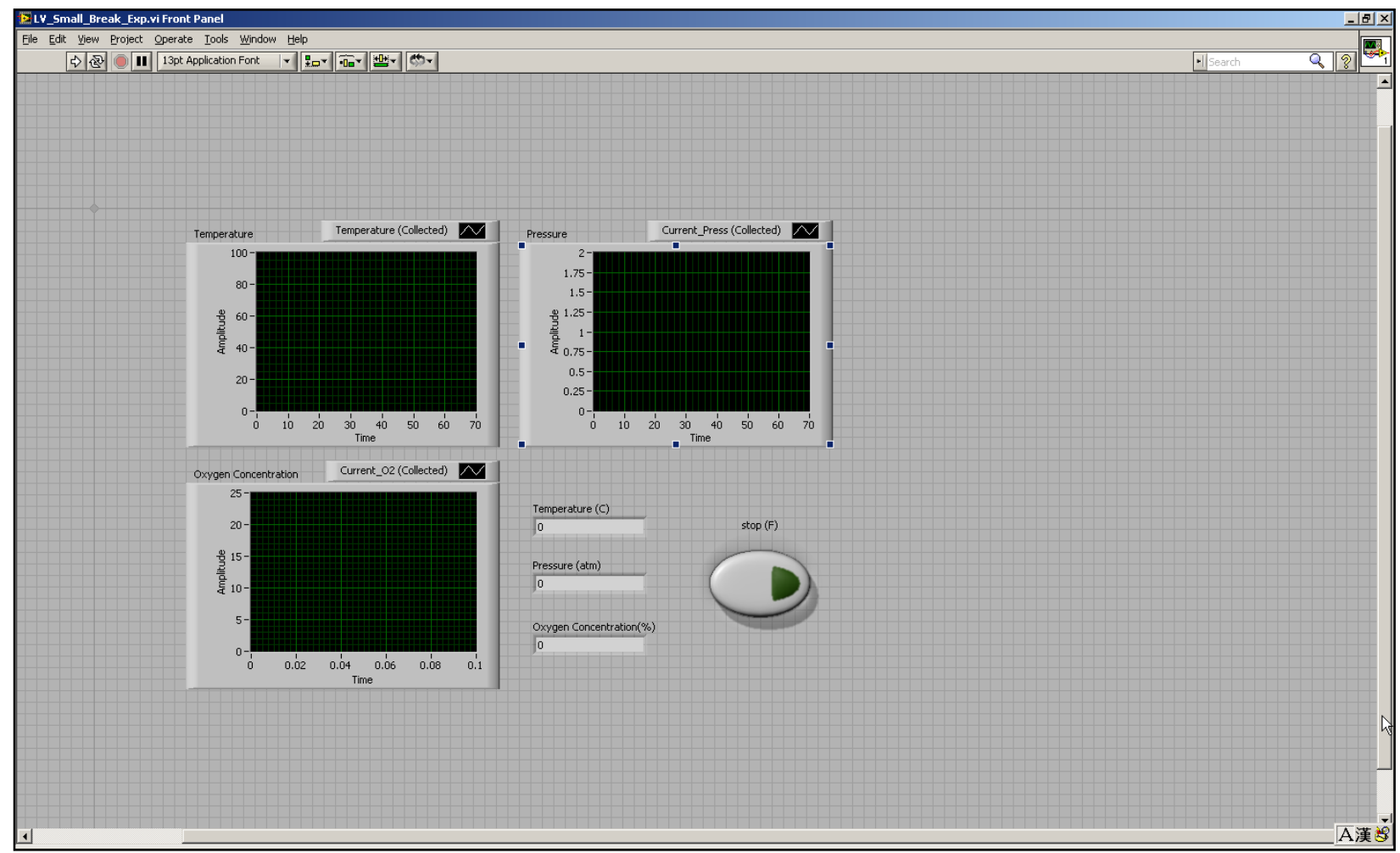

Figure 2-15. Screenshot of the Labview program for small break air-ingress experiment. 


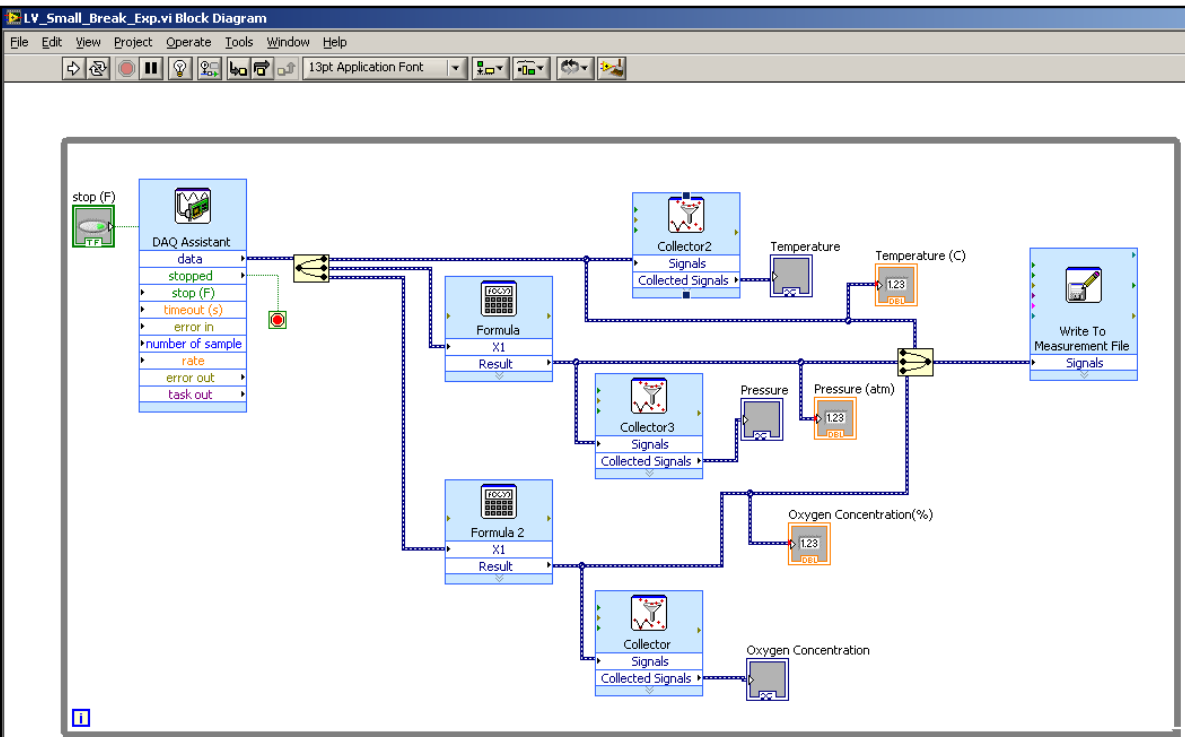

Figure 2-16. Screenshot of the Labview program for small break air-ingress experiment (model diagram).

\subsection{Data Analysis Method}

This section summarizes the method used to analyze data for the small break air-ingress experiment.

During the experiment, change of oxygen concentration was measured in the test section. Using the measured oxygen concentration, a mole fraction of air in the test section was estimated as

$$
f_{\text {air }}=\frac{C_{O_{2}}}{C_{O_{2}, \infty}}
$$

where:

$f_{\text {air }}=$ air mole fraction in the test section

$C_{O 2}=$ oxygen concentration in the test section (\%)

$C_{O 2, \infty}=$ oxygen concentration in the environment (\%).

Helium mole fraction was estimated by the expression

$f_{\text {he }}=1-f_{\text {air }}$

where $f_{h e}=$ helium mole fraction in the test section

Volumes of air and helium in the test section were estimated by the expressions:

$V_{\text {he }}=V_{\text {total }} \cdot f_{\text {he }}=V_{\text {total }} \cdot\left(1-f_{\text {air }}\right)$ 
and

$$
V_{\text {air }}=V_{\text {total }} \cdot f_{\text {air }}
$$

where:

$$
\begin{aligned}
& V_{\text {he }}=\text { helium volume in the test section }\left(\mathrm{m}^{3}\right) \\
& V_{\text {air }}=\text { air volume in the test section }\left(\mathrm{m}^{3}\right) \\
& V_{\text {total }}=\text { total volume in the test section }\left(\mathrm{m}^{3}\right) .
\end{aligned}
$$

Change of air volume in the test section was estimated by the expression

$$
\frac{d V_{\text {air }}}{d t}=\frac{d}{d t}\left(V_{\text {total }} \cdot f_{\text {air }}\right)=V_{\text {total }} \cdot \frac{d f_{\text {air }}}{d t} .
$$

Since the pressure in the test-section is maintained during the experiment, the inflow and outflow were balanced as

$\dot{V}_{\text {in }}=\dot{V}_{\text {out }}=\dot{V}_{\text {ex }}$

where:

$\dot{V}_{\text {in }}=$ volumetric flow rate of air into the test-section $\left(\mathrm{m}^{3}\right)$

$\dot{V}_{\text {out }}=$ volumetric flow rate of air/helium mixture out of the test section $\left(\mathrm{m}^{3}\right)$

$\dot{V}_{e x} \quad=$ exchange volumetric flow rate through the test-section hole $\left(\mathrm{m}^{3}\right)$.

Therefore, the volumetric flow rate of air into the test-section (or exchange volumetric flow rate) was obtained by

$\frac{d V_{\text {air }}}{d t}=\dot{V}_{\text {in }}-f_{\text {air }} \cdot \dot{V}_{\text {out }}=\left(1-f_{\text {air }}\right) \cdot \dot{V}_{\text {in }}=V_{\text {total }} \cdot \frac{d f_{\text {air }}}{d t}$

and

$\dot{V}_{\text {in }}=\frac{V_{\text {total }}}{\left(1-f_{\text {air }}\right)} \cdot \frac{d f_{\text {air }}}{d t}$.

Mass flow rate of air into the test section through the hole was estimated by the expression

$\dot{m}_{\text {air }}=\rho_{\text {air }} \cdot \dot{V}_{\text {in }}=\frac{\rho_{\text {air }} \cdot V_{\text {total }}}{\left(1-f_{\text {air }}\right)} \cdot \frac{d f_{\text {air }}}{d t}$

where $\dot{m}_{\text {air }}=$ mass flow rate of air into the test section $(\mathrm{kg} / \mathrm{s})$.

Average velocity of air into the test section through the hole was estimated by the expression

$U_{\text {air }}=\frac{\dot{m}_{\text {air }}}{\rho_{\text {air }} \cdot A_{\text {hole }}}=\frac{V_{\text {total }}}{A_{\text {hole }} \cdot\left(1-f_{\text {air }}\right)} \frac{d f_{\text {air }}}{d t}$ 
where:

$U_{\text {air }}=$ average velocity of air into the test section $(\mathrm{m} / \mathrm{s})$

$A_{\text {hole }}=$ surface area of the hole $\left(\mathrm{m}^{2}\right)$.

Hole surface area in Equation (2-7) was then calculated by the expression

$A_{\text {hole }}=\frac{\pi \cdot d_{\text {hole }}^{2}}{4}$

where $d_{\text {hole }}=$ hole diameter $(\mathrm{m})$.

\subsection{Experimental Results and Discussions}

Figures 2-17, 2-18, and 2-19 show overall the air mole fraction in the test loop during the experiment for a 1/2-inch diameter $(d)$ hole. The $\mathrm{x}$-axis in the figures represents time and y-axis represents the air mole fractions. The flow rates were 3.5, 5.0, and $6.5 \mathrm{slpm}$. Average flow speeds through the test-section made of a 2 inch pipe were estimated to be $0.029,0.41,0.53 \mathrm{~m} / \mathrm{s}$, respectively. The experimental data were obtained for five different hole angles from 0 degrees (at the bottom) to 180 degrees (at the top) as seen in Figure 2-8. General trends of the experimental data are as follows:

- Air mole fractions in the test loop increased with time as air gradually ingressed into the test loop through the hole on the test section. The air ingress increase rate was lowest at 0 degrees and the highest at 135 degrees.

- Air mole fraction rates decreased with time. The main reason is the decrease of density differences between inside and outside of the test loop.

- The effect of the angular location of the holes decreased as the flow rate increases. This phenomenon is presently under investigation.

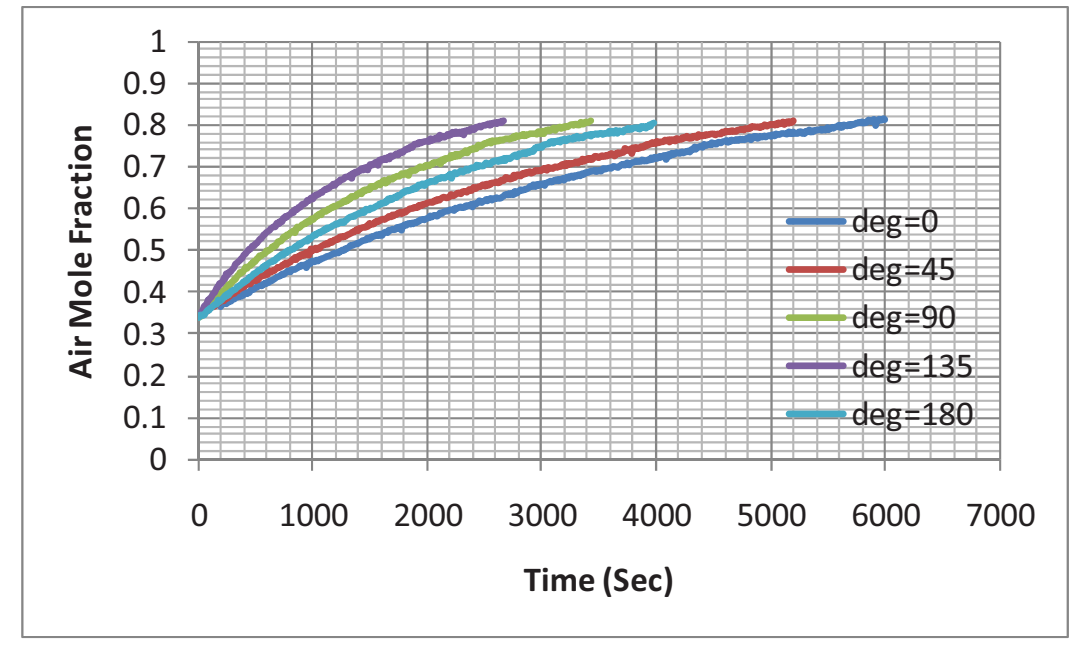

Figure 2-17. Time vs. air mole fraction ( $d=1 / 2$ inch, $3.5 \mathrm{slpm}$ ). 


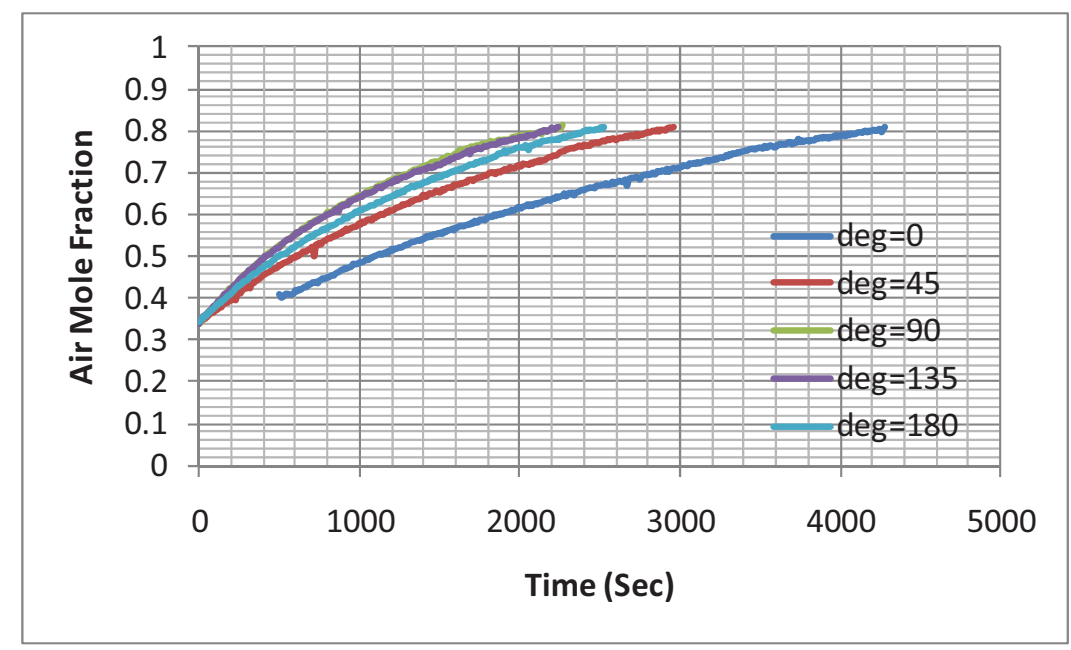

Figure 2-18. Time vs. air mole fraction ( $d=1 / 2$ inch, 5.0 slpm).

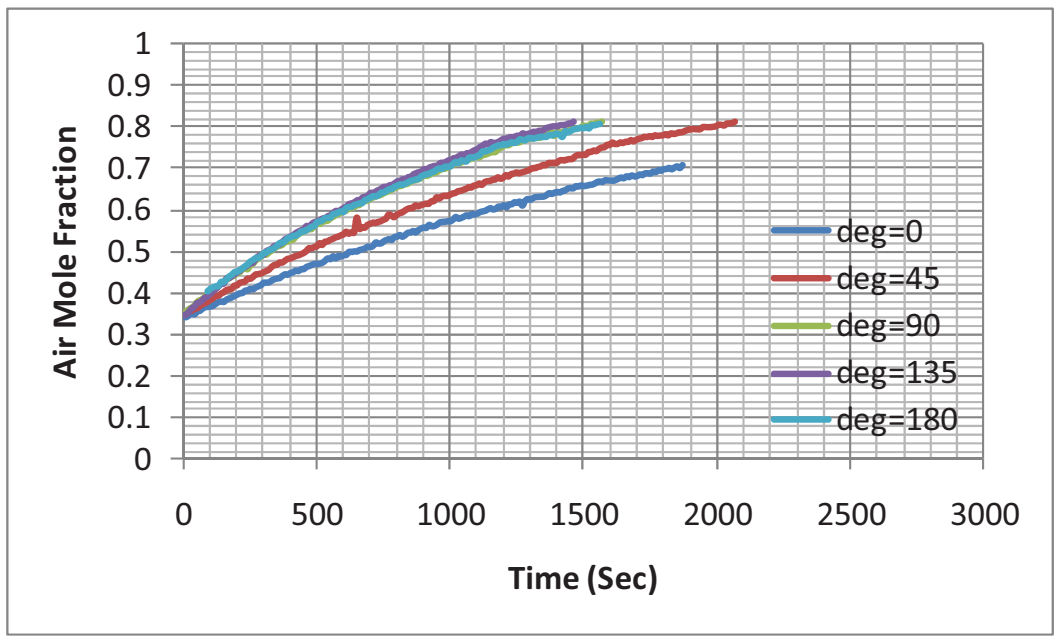

Figure 2-19. Time vs. air mole fraction ( $d=1 / 2$ inch, $6.5 \mathrm{slpm}$ ).

Using Equation (2-5), air volume changes in the test loop $\left(d V_{\text {air }} / d t\right)$ can be estimated from the experimental data. More detailed definitions of this parameter can be seen in Section 2.5. Figures 2-20, 221, 2-22 show measured air volume changes $\left(d V_{\text {air }} / d t\right)$ for various density ratios. Some notable results are as follows:

- Air volume changes in the test loop decreased with density ratio because of a decreasing driving force (density gradient). The rate change is very linear.

- The maximum air volume change was observed for the hole angle of 135 degrees and the minimum, for 0 degrees. The effect of the holes, i.e., the angular location, is significant at lower density ratios (= higher density difference). However, it becomes trivial at higher density ratios because lower driving force diminishes the effect of density gradient driven flow. 


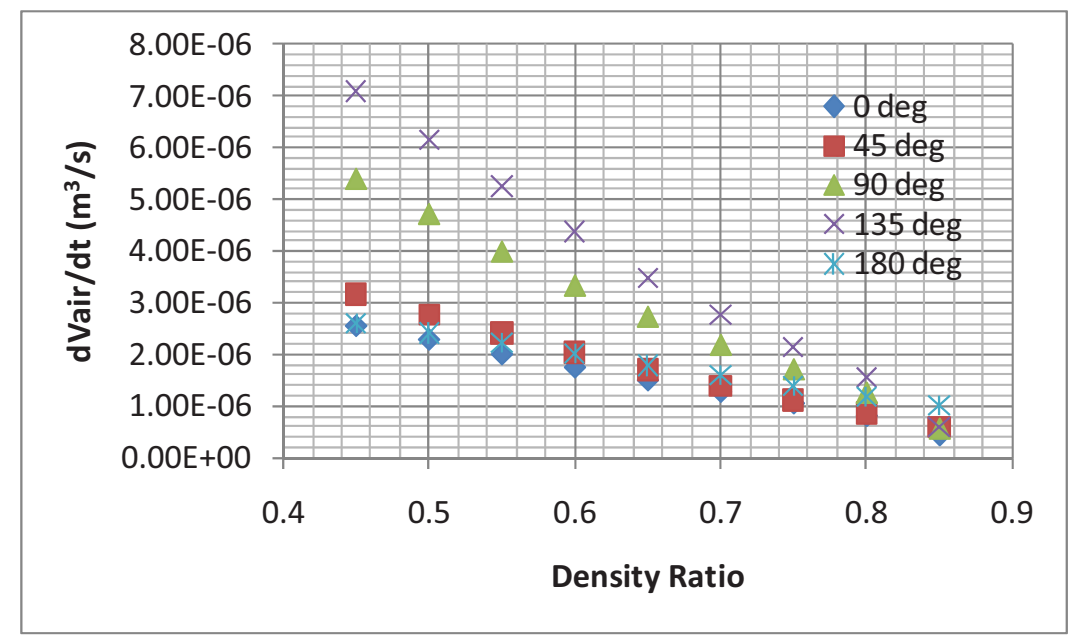

Figure 2-20. Density ratio vs. $d V_{\text {air }} / d t(d=1 / 2$ inch, 3.5 s/pm).

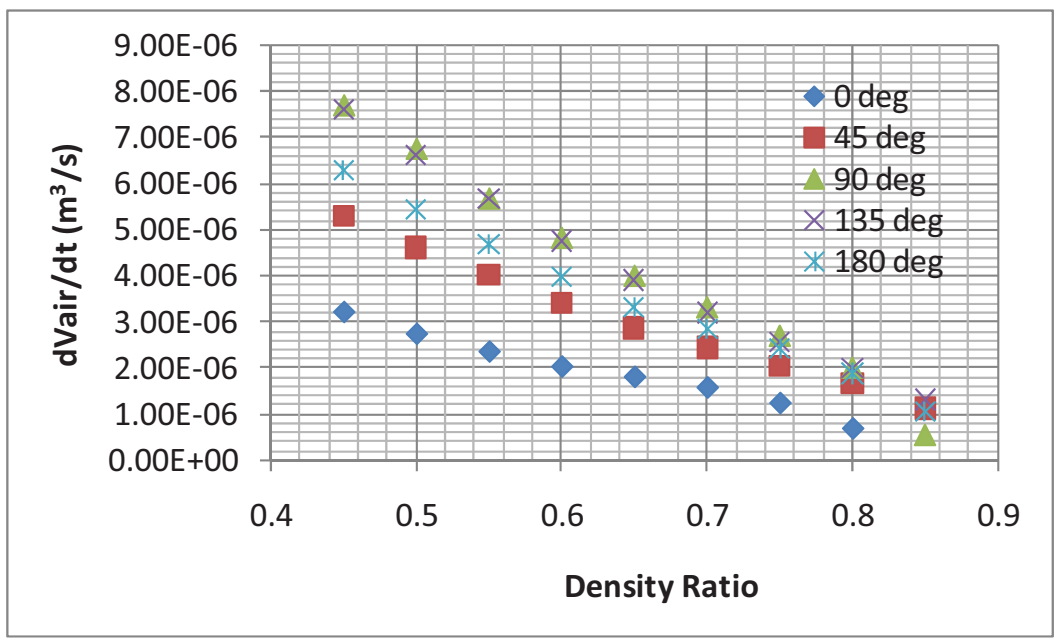

Figure 2-21. Density ratio vs. $d V_{\text {air }} / d t(d=1 / 2$ inch, 5.0 s/pm).

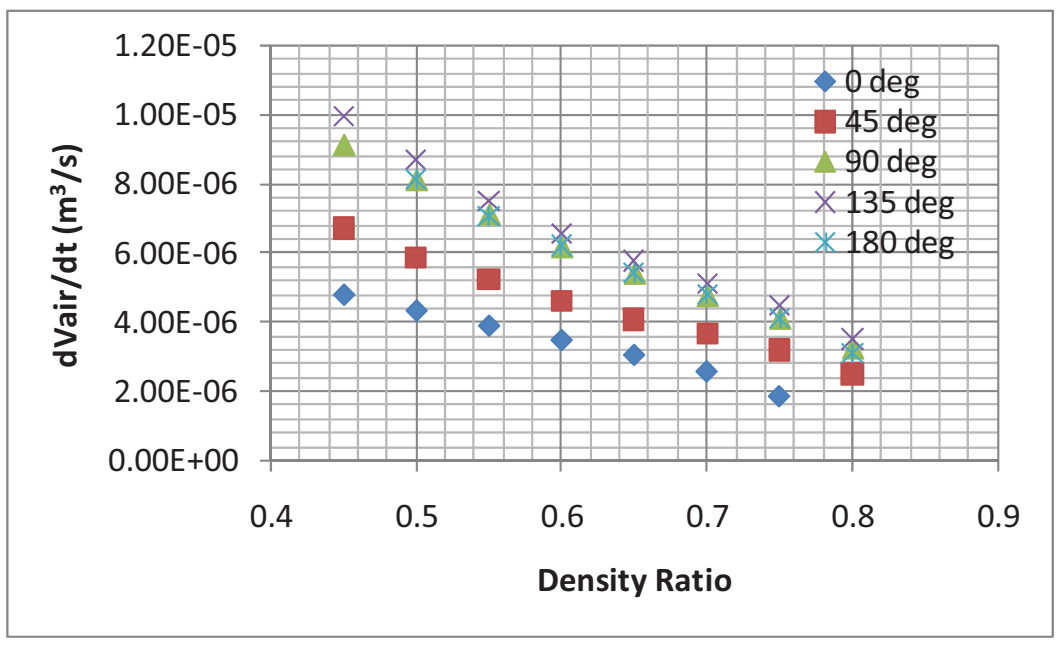

Figure 2-22. Density ratio vs. $d V_{\text {air }} / d t(d=1 / 2$ inch, 6.5 slpm). 
Figure 2-23 shows the angle effect on the air volume changes in the test facility. In this graph, the $\mathrm{x}$-axis is a hole angle and the $\mathrm{y}$-axis is the air volume change. This figure explains the following:

- Air volume changes in the test loop gradually increase from 0 to 135 degrees with angles then decrease from 135 to 185 degrees. Increase of stratified flow effect is the main reason for the increase of air volume changes from 0 to 135 degrees. Flow confliction between heavy downward flow and light upward flow is the main reason for decreasing air volume changes from 135 to 180 degrees.

- The maximum air volume change is observed for 135 degrees in a hole angle and the minimum, for 0 degrees.

- The air volume changes were not significantly low, even for the 0 degrees, showing that the airingress mechanism is not in the molecular diffusion controlled regime. There are some reasons for this. First, the hole at the bottom has a curvature, so density gradient effect still exists from the bottom holes, even though it is not significant. Second, there is instability when the flow passes through the hole. It generates repeated flow mixing through the hole, even though the flow speed is only $0.029 \mathrm{~m} / \mathrm{s}$, which is generally within natural circulation flow ranges. In the previous computational studies, it was assumed that there is no flow in the channel so the flow instability was not captured and the air-ingress was dominated by molecular diffusion.

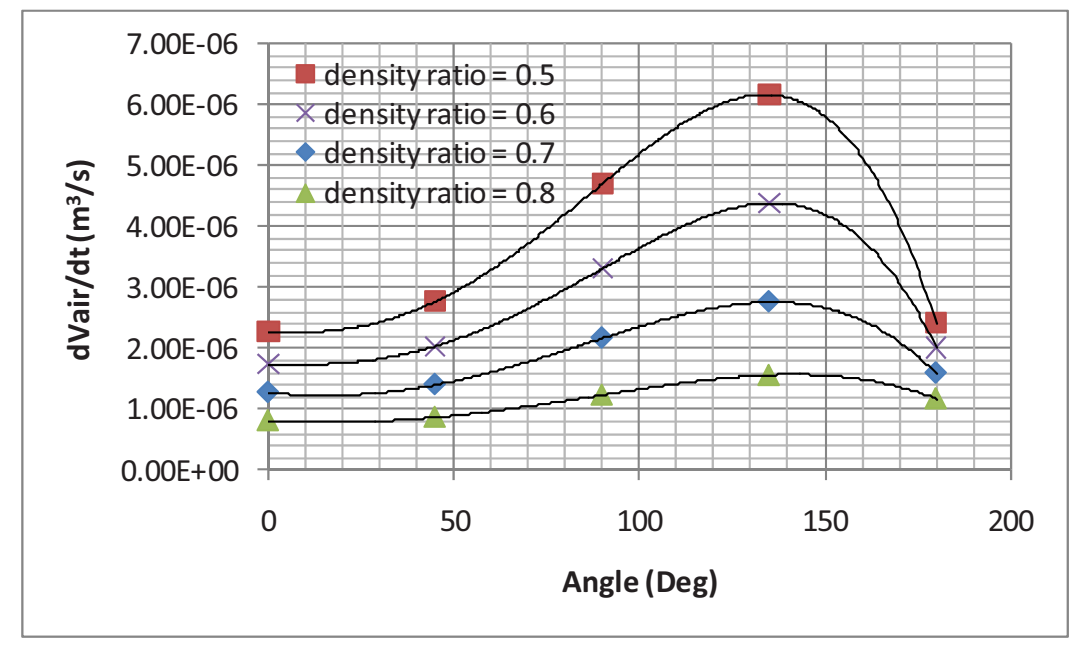

Figure 2-23. Angle vs. $d V_{\text {air }} / d t(d=1 / 2$ inch, $3.5 \mathrm{slpm})$.

Figures 2-24 and 2-25 show the flow rate effects on the air volume changes in the test loop. The result shows that the higher flow rate leads to the higher air-ingress rate into the test facility. The increase of the air-ingress rate with the flow rate looks contributed to the increase of flow instability around the hole when the flow passed through it.

Using Equation (2-7), volumetric air ingress flow rate $\left(\dot{V}_{\text {in }}\right)$ into the test-section (or exchange volumetric flow rate) can be estimated from the experimental data. Figures 2-20, 2-21, and 2-22 show $\dot{V}_{\text {in }}$ for various density ratios. Some notable results are summarized as follows:

- Air ingress rate through the hole slightly decreases with density ratio because of the density gradient reduction. For the angles above 45 degrees, the density ratio effect becomes more significant. On the other hand, as the flow rate increases, the density ratio becomes less effective. One of the main reasons considered is that at higher flow rates, the air ingress could be more affected by flow instability generated around the hole.

- The maximum air ingress rate observed is 135 degrees in a hole angle and the minimum is 0 degrees. 


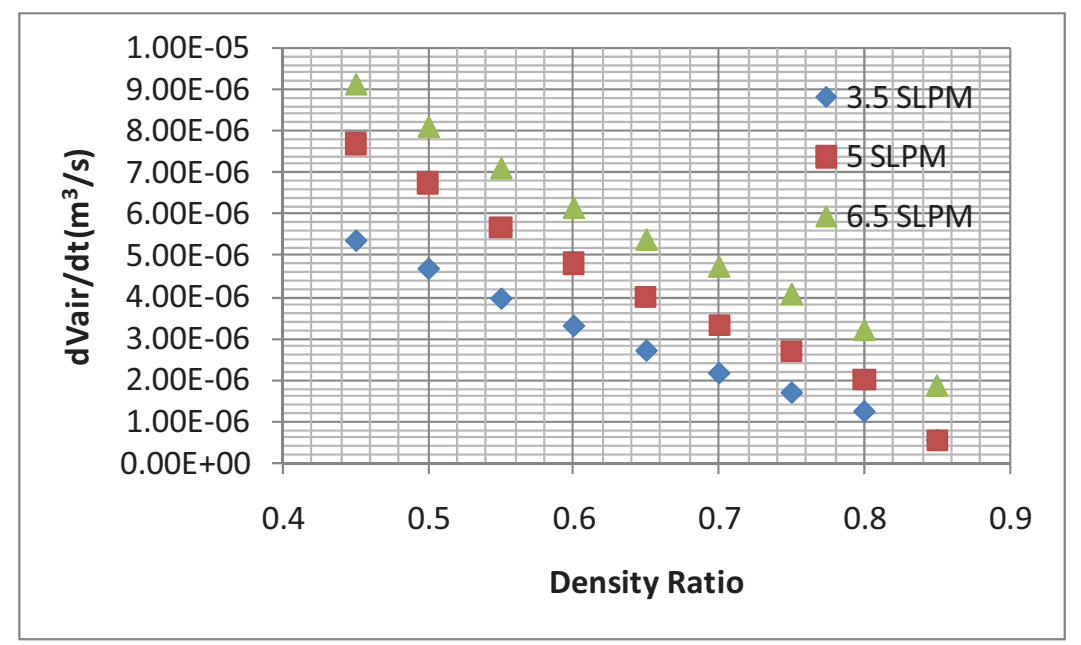

Figure 2-24. Density ratio vs. $\mathrm{dV}_{\text {air }} / \mathrm{dt}(\mathrm{d}=1 / 2$ inch, 90 degrees).

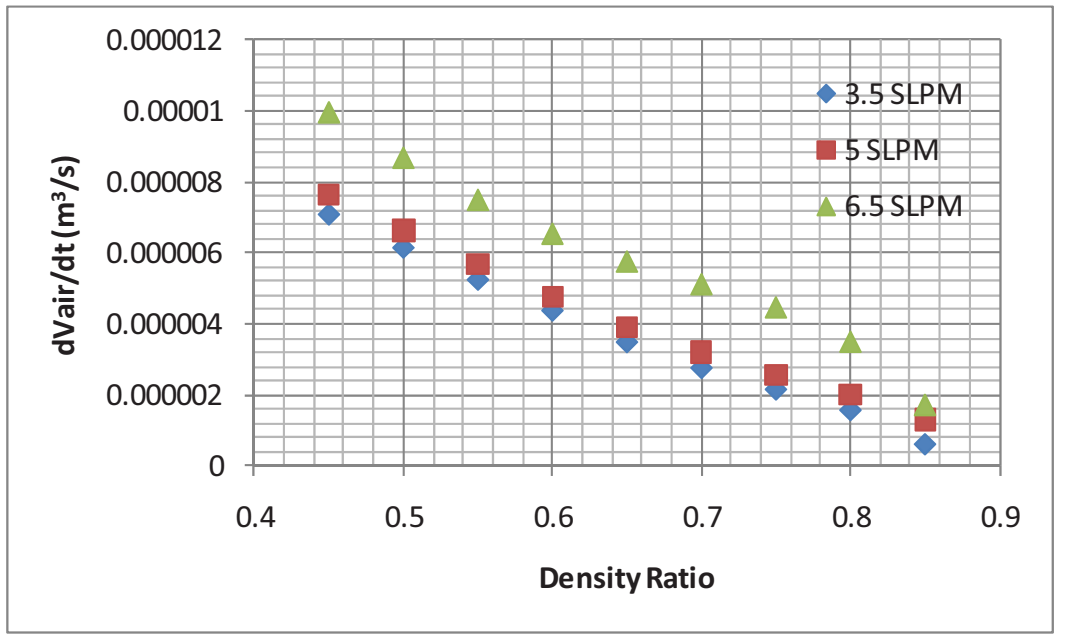

Figure 2-25. Density ratio vs. $d V_{\text {air }} / d t(d=1 / 2$ inch, 135 degrees).

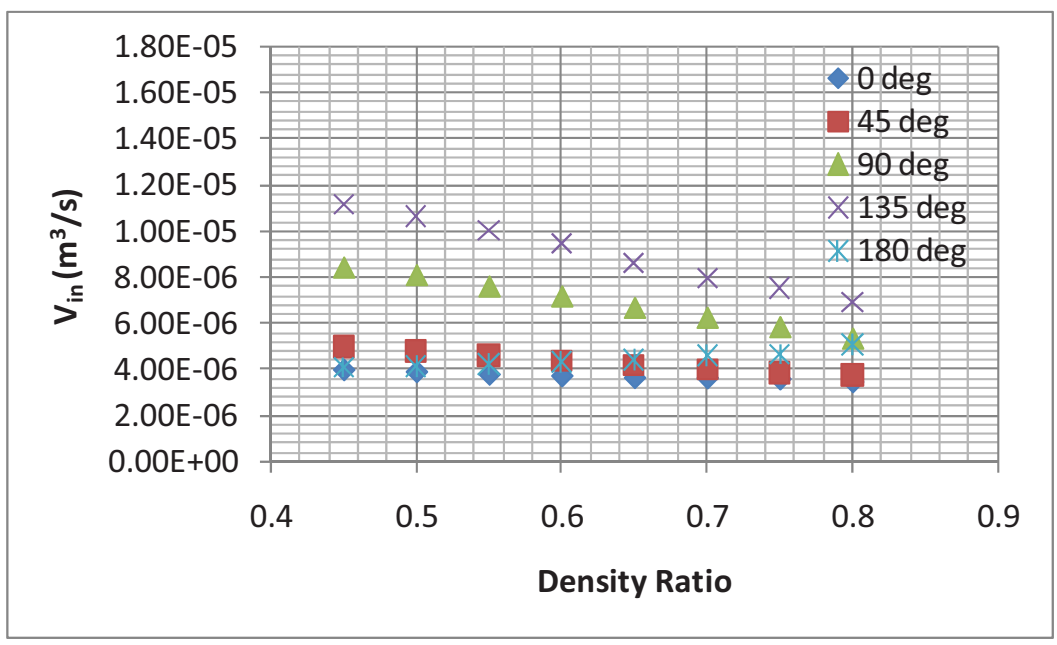

Figure 2-26. Density ratio vs. $\dot{V}_{\text {in }}(\mathrm{d}=1 / 2 \mathrm{inch}, 3.5 \mathrm{slpm})$. 


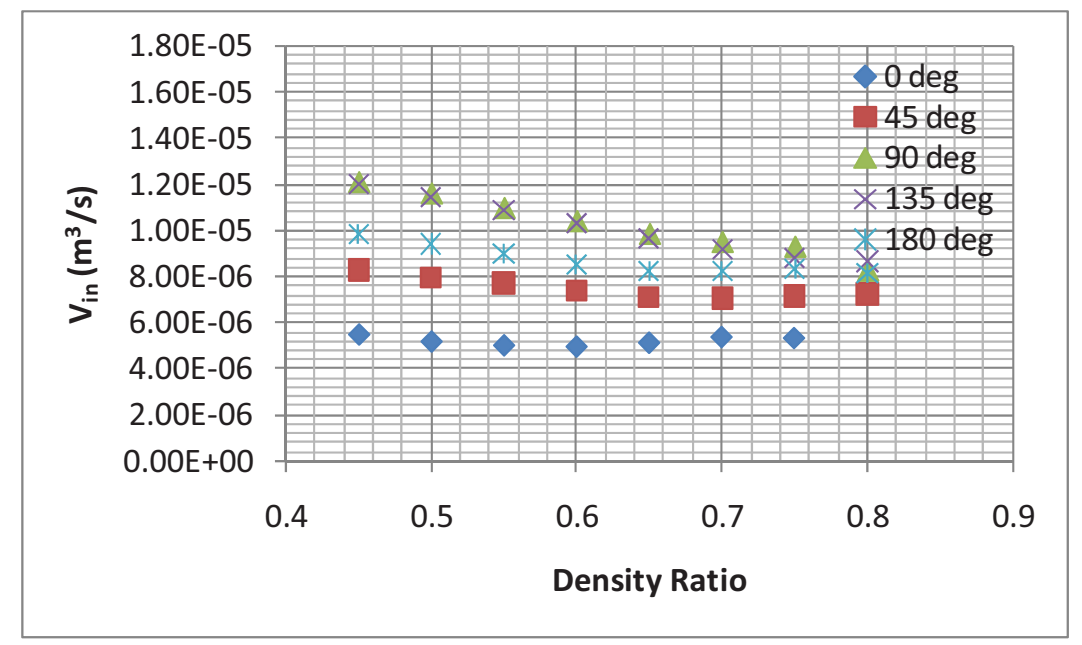

Figure 2-27. Density ratio vs. $\dot{V}_{\text {in }}(\mathrm{d}=1 / 2$ inch, $5.0 \mathrm{slpm})$.

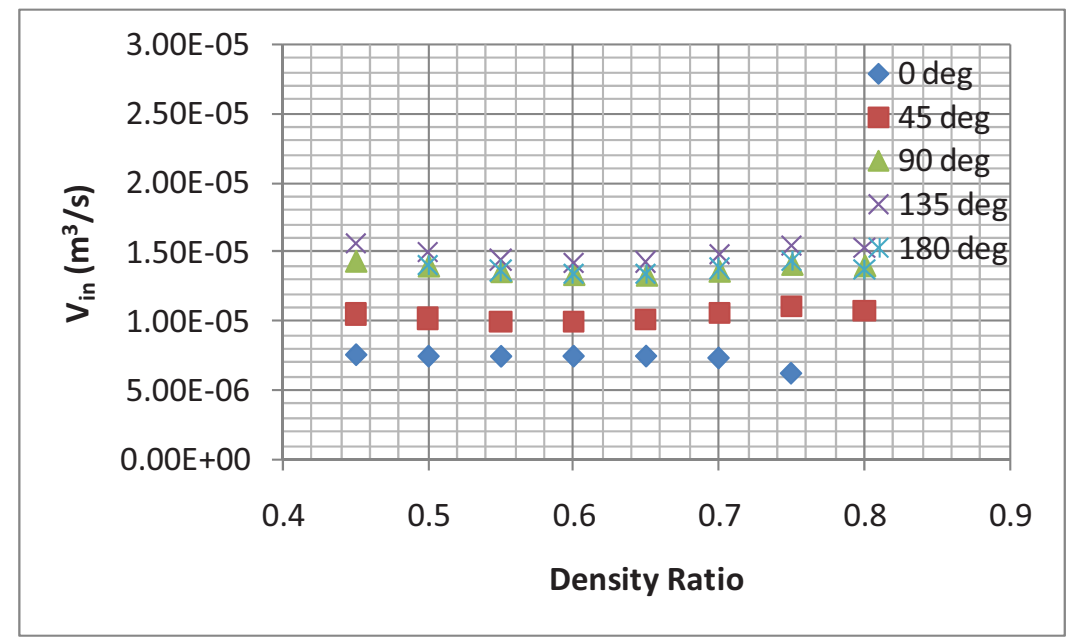

Figure 2-28. Density ratio vs. $\dot{V}_{\text {in }}(\mathrm{d}=1 / 2$ inch, $6.5 \mathrm{slpm})$.

Figures 2-29 shows the air ingress rates for different hole angles. The following summarizes the notable results:

- Air ingress rate increases with angles from 0 to 135 degrees then decreases from 135 to 185 degrees. For all cases, the maximum air-ingress rates are observed for 135 degrees. Decrease of air-ingress rate above 135 degrees is because of flow confliction between heavy downward flows and light upward flows.

- The maximum air ingress rate is observed for 135 degrees and the minimum for 0 degrees.

- Even for the 0 degrees angle, the air-ingress speeds were still not very slow, meaning that the flow regime is not in the molecular diffusion even in this case, where the break is at the bottom. There are some reasons for this. First, the hole at the bottom has a curvature so the density gradient effect still exists for the bottom holes. Second, there is instability when the flow passes through the hole; it generates repeated flow mixing through the hole even though the flow speed is only $0.029 \mathrm{~m} / \mathrm{s}$, which is generally within natural circulation flow ranges. 


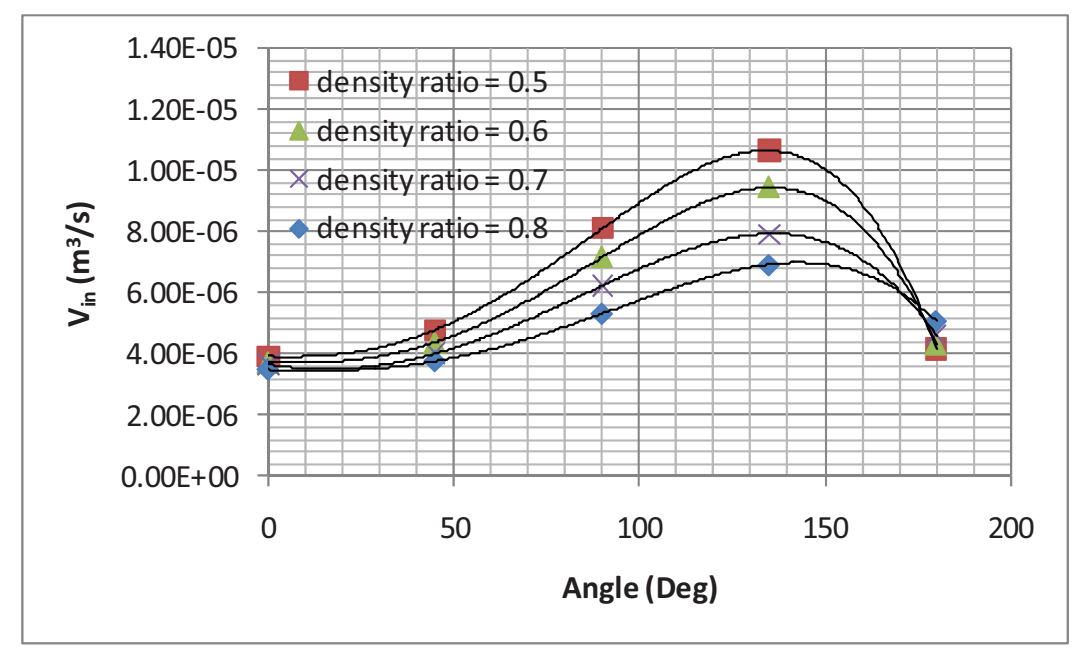

Figure 2-29. Angle vs. $\dot{V}_{\text {in }}$ (d = 1/2 inch, 3.5 slpm).

Figures 2-30 and 2-31 show the effects of flow rates on the air ingress rates through the hole. The result shows that the higher flow rate results in the higher air-ingress rate into the test facility. The increase of the air-ingress rate with the flow rate looks contributed to an increase of flow instability around the hole when the flow passed through it.

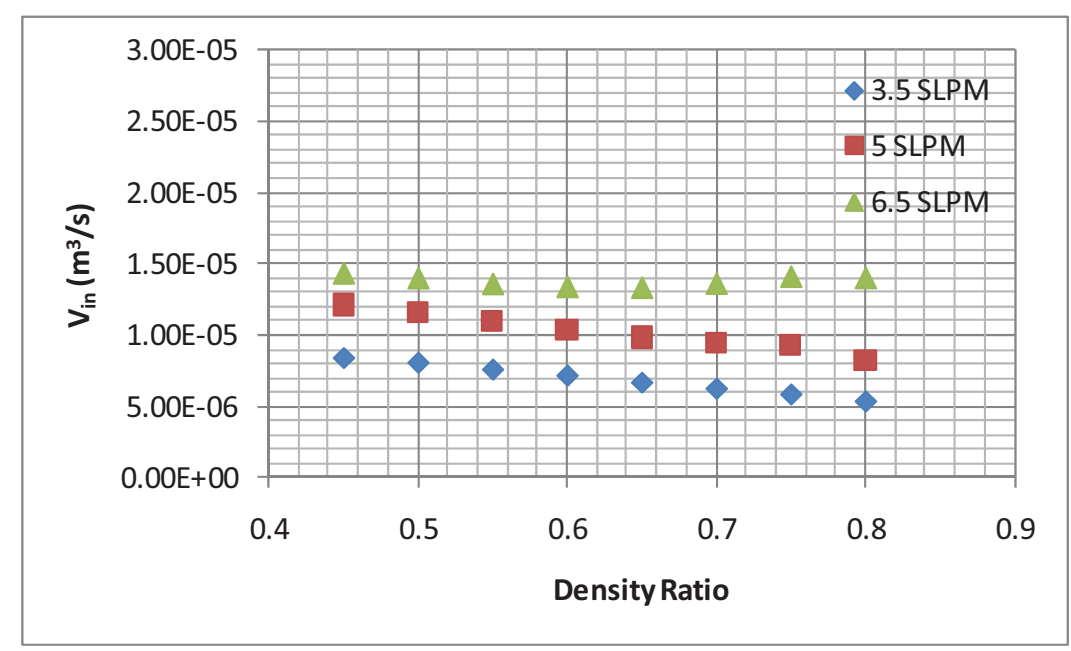

Figure 2-30. Density ratio vs. $\dot{V}_{\text {in }}$ (d =1/2 inch, 90 degrees). 


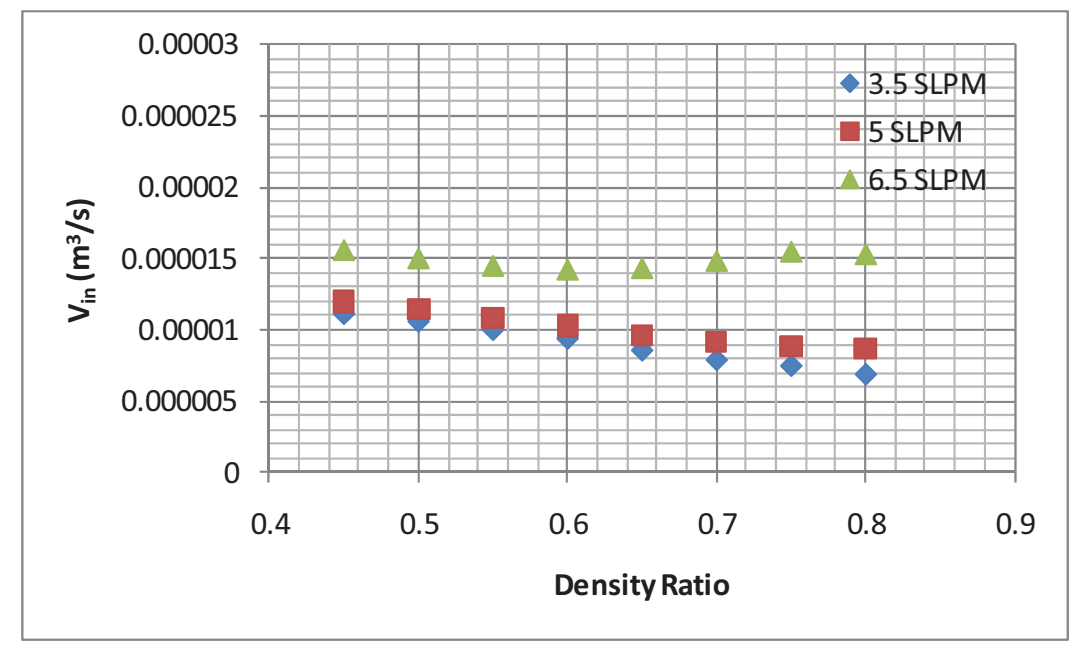

Figure 2-31. Density ratio vs. $\dot{V}_{\text {in }}(\mathrm{d}=1 / 2$ inch, 135 degrees).

In order to investigate the hole diameter effect on the air-ingress rates, some experiments were performed using some other test-sections with different hole sizes. The following summarizes the results.

- Figures 2-32 and 2-33 show air volume changes in the test loop during the experiment for $\mathrm{d}=$ $3 / 8$ inch and $d=1 / 4$ inch, respectively. As shown in these figures, the air volume changes in the test loop increase from 0 to 120 degrees, then decreases from 120 to 180 degrees. One notable result is that the angle effect is very slight for the smallest hole size $(\mathrm{d}=1 / 4)$. It shows that the density gradient driven flow effect is getting smaller with the hole size reduction.

- Figures 2-34 and 2-35 show the air-ingress flow rates through the holes for $\mathrm{d}=3 / 8$ inch and $\mathrm{d}=1 / 4 \mathrm{inch}$, respectively. The trends of the graphs are the same as the ones shown in Figures 2-32 and 2-33 for the air volume changes. However, effects of density ratios on the air ingress rates were not significant compared to the angles according to the experimental data.

- Figure 2-36 and 2-37 show the effects of hole diameters. The air-ingress rate is higher for the larger hole diameter because of larger density gradient and flow exchange area. However, because of limited experimental data, quantitative analysis has not been performed here yet. Future studies are therefore recommended.

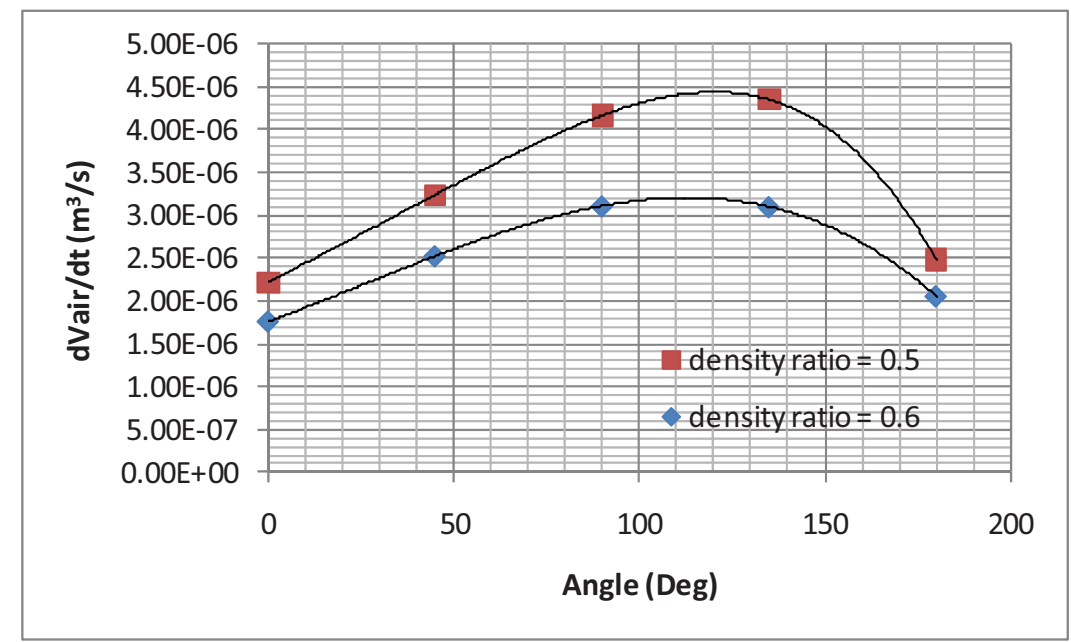

Figure 2-32. Angle vs. $d V_{\text {air }} / d t(d=3 / 8$ inch, 3.5 s/pm). 


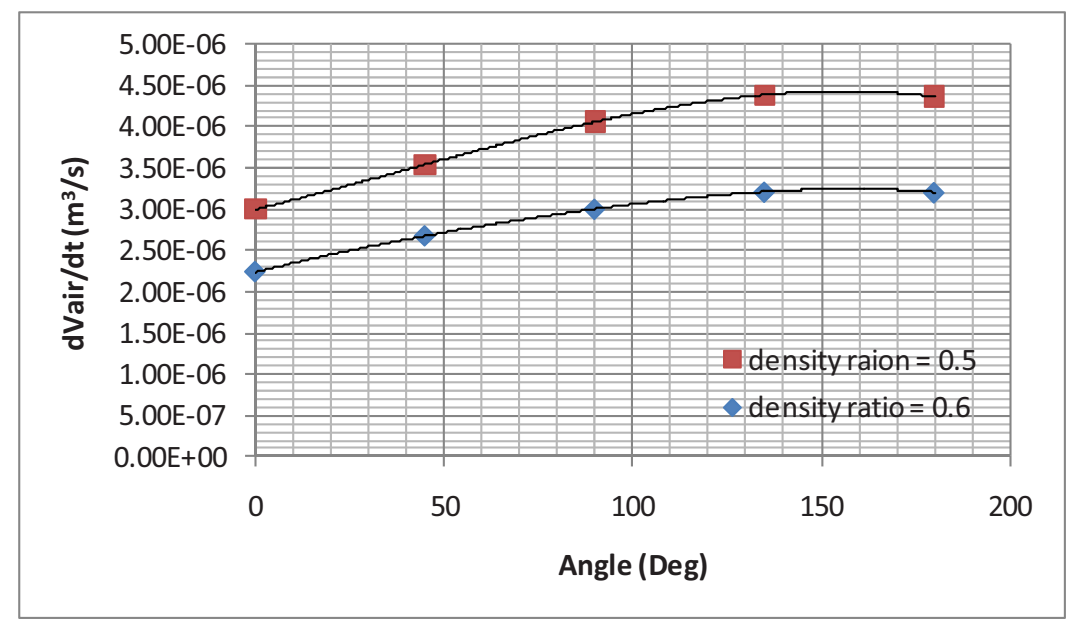

Figure 2-33. Angle vs. $d_{\text {air }} / d t(d=1 / 4$ inch, $3.5 \mathrm{slpm})$.

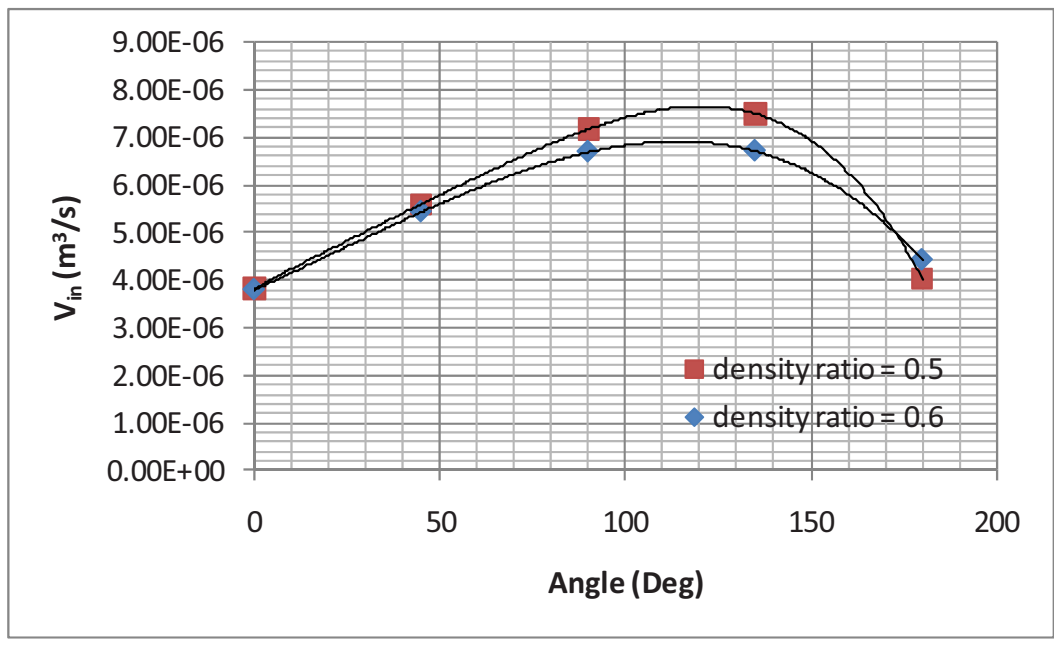

Figure 2-34. Angle vs. $\dot{V}_{\text {in }}$ (d = 3/8 inch, 3.5 slpm).

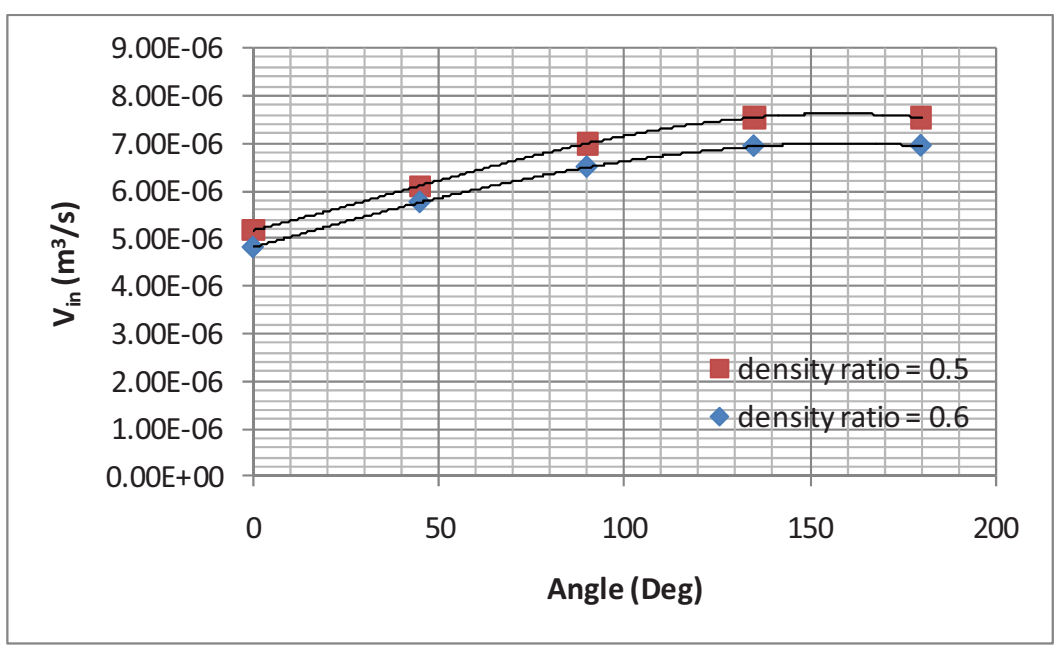

Figure 2-35. Angle vs. $\dot{V}_{\text {in }}$ (d = 1/4 inch, 3.5 slpm). 


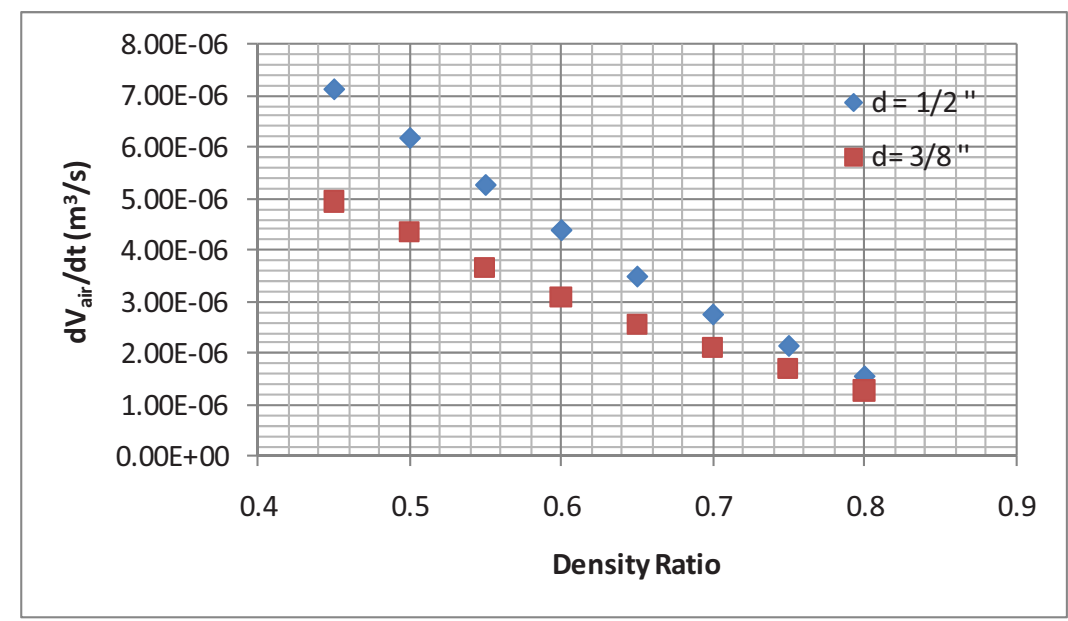

Figure 2-36. Effect of Hole Diameters.

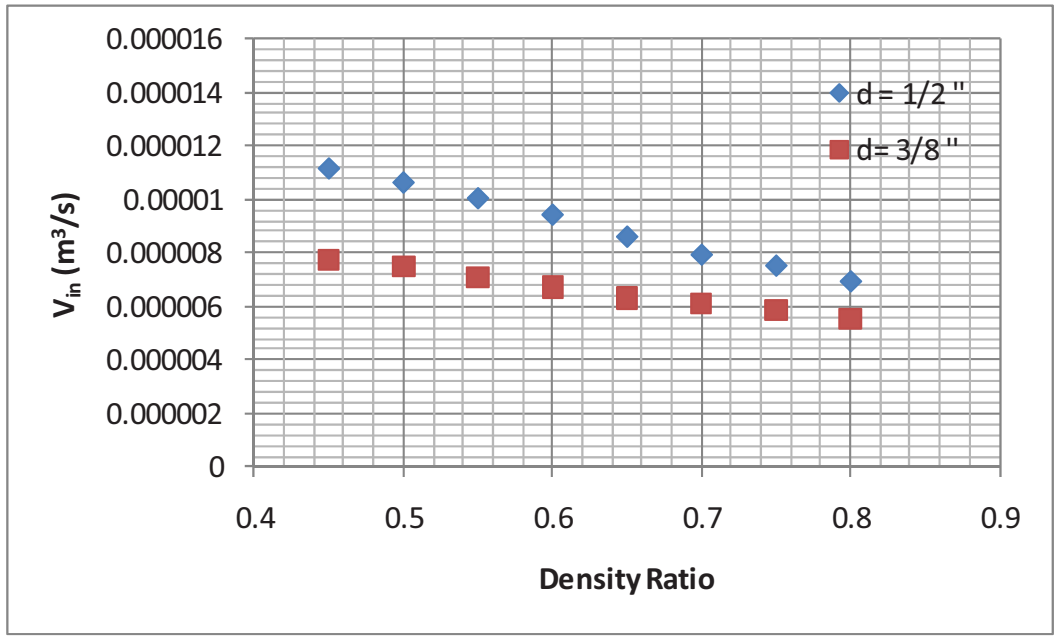

Figure 2-37. Effect of Hole Diameters. 


\section{OVERALL SUMMARY}

The small break air-ingress experiment was designed to investigate air-ingress phenomena that might occur in small pipe break situations in VHTRs. The experiment measured air-ingress rates through a small hole in a broken pipe model in various flow and break conditions. Several important parameters, including break orientation, break size, main flow velocity, and tube thickness, were investigated by this experiment. The data gleaned will be used to help in understanding air-ingress phenomena in small break situations and to assess/validate CFD codes or system analysis codes.

The general approach of this experiment was to monitor variations of oxygen concentrations in the helium flow circulation system with oxygen sensors (or detectors) in order to obtain air-ingress rates through the test-section. The test-section was basically a pipe with small holes. In order to consider various pipe break situations, the experiment used several test-sections having different hole diameters and pipe thicknesses. The test-section was rotatable so the radial position of the hole could be easily adjusted. The experiment was conducted at room temperature and atmospheric pressure. The oxygen concentration and flow rate data were stored in the computer by a DAS.

From this study, lots of experimental data were obtained for the small break air-ingress situations. The following summarizes some notable results:

- Effect of hole orientation: Hole orientation significantly affects air ingress mechanisms and rates. According to the experimental observation, the air ingress rate increases with hole angles from 0 to 135 degrees accompanied by an enhanced density gradient driven flow effect. For angles higher than 135 degrees, the air ingress rate starts to decrease sharply because of flow conflictions through the hole changing the air ingress mechanism to intermittent flow. The experimental results also show that the air ingress rate for the bottom break is not significantly low, unlike predicted results by previous computational works. This is because of a curvature of the hole and the flow instability around the bottom hole. Since the previous computational studies were based on the stagnant flow in the channel, this instability effect could not be captured.

- Effect of hole size: The general trend of the experimental results showed that increasing the hole size increases the air ingress rate. This result is attributed to a larger flow exchange surface area and density gradient effect. However, effects of density ratios on the air ingress rates were not significant compared to the hole orientations. Only limited numbers of experimental data were obtained for this effect. Future studies are therefore recommended to collect sufficient data for more quantitative analysis.

- Effect of flow rates: Increased flow rates inside the channel increase the air-ingress rate. The increased the air-ingress rate caused by the increased flow rate appears to be caused by the increased flow instability around the hole when the flow passes through it. Because of the flow inside the channel, molecular diffusion controlled regimes were not observed in the small break air-ingress experiment, even though the flow speed is as low as $0.029 \mathrm{~m} / \mathrm{s}$, which is within the range of general natural circulation flow.

The data obtained from this experiment will be compared to the CFD codes for predicting density gradient driven flow phenomena in future small break situations. Experimental works will also be continued to better understand this phenomena. Collected experimental data will eventually be used on the development of analytical or empirical models for use in future systems analysis codes. 


\section{REFERENCES}

Oh, C. H., E. S. Kim, S., H. C. NO, and N. Z. Cho, 2009, Experimental Validation of Stratified Flow Phenomena, Graphite Oxidation, and Mitigation Strategies of Air Ingress Accident, Final Report, INL/EXT-10-19289, Idaho National Laboratory, December, 2010.

Schultz, R. R., et al., 2006, Next Generation Nuclear Plant Methods Technical Program Plan, INL/EXT-06-11804, September 2006. 